\title{
Sequential Two-Step Stereoselective Amination of Allylic Alcohols through Combination of Laccases and Amine
}

\section{Transaminases}

\author{
Jesús Albarrán-Velo, ${ }^{[a]}$ Iván Lavandera*[a] and Vicente Gotor-Fernández ${ }^{*[a]}$
}

\begin{abstract}
A sequential two-step chemoenzymatic methodology has been described for the stereoselective synthesis of $(3 E)-4$ (het)arylbut-3-en-2-amines in a highly selective manner and under mild reaction conditions. The approach consists in the oxidation of the corresponding alcohol precursors using the catalytic system composed by the laccase from Trametes versicolor and the oxyradical TEMPO, followed by the asymmetric biotransamination of the corresponding ketone intermediates. Optimisation of the oxidation reaction, exhaustive amine transaminase screening for the biotransaminations and the compatibility of both enzymatic reactions have been deeply studied, searching for the design of a compatible sequential cascade. This synthetic strategy has been successfully achieved, the combination of enzymes displaying a broad substrate scope as 16 chiral amines have been obtained in moderate to good isolated yields (29-75\% isolated yield) and excellent enantiomeric excess (94->99). Interestingly, both amine enantiomers can be achieved depending on the selectivity of the amine transaminase employed in the system.
\end{abstract}

\section{Introduction}

The chemical preparation of allylic amines has traditionally attracted great attention, ${ }^{[1,2]}$ due to the presence of this motif in numerous biologically active and natural products. ${ }^{[3-8]}$ In addition, their versatility in chemical synthesis has been largely demonstrated based on their multiple applications for the preparation of valuable nitrogen-containing organic compounds..$^{[9-11]}$ In this context, the stereoselective synthesis of $(3 E)$-4-arylbut-3-en-2-amine derivatives is particularly challenging, and it has been described through a series of metalcatalysed methodologies including kinetic resolutions through acylation ${ }^{[12]}$ and alkylation processes, ${ }^{[13]}$ or asymmetric synthesis via Claissen rearrangements, ${ }^{[14]}$ dehydroxybenzotriazolylation, ${ }^{[15]}$ hydrogenation, ${ }^{[16,17]}$ hydroamination, ${ }^{[18]}$ alkenylation reactions, ${ }^{[19]}$ and azidation of allylic esters, ${ }^{[20]}$ among others.

[a] J. Albarrán-Velo, Dr. I Lavandera, ${ }^{*}$ Dr. V. Gotor-Fernández Organic and Inorganic Chemistry Department University of Oviedo

Avenida Julián Clavería 8, 33006 Oviedo, Spain E-mail: lavanderaivan@uniovi.es (I.L.) and vicgotfer@uniovi.es (V.G.-F.)

Supporting information for this article is given via a link at the end of the document.
Biocatalytic methods have appeared as a sustainable solution for the synthesis of chiral amines by means of the single action of several enzyme classes including lipases, amine transaminases (ATAs), amine oxidases, amine dehydrogenases, imine reductases or reductive aminases, ${ }^{[21-26]}$ but interestingly in recent years great devotion has been put towards the synthesis of chiral amines through chemo-, photo- and multienzymatic approaches. ${ }^{[27-33]}$ As an example, the selective amination of racemic sec-alcohols has been described through elegant cascades via combination of an alcohol dehydrogenasecatalysed oxidation into ketones with a subsequent bioamination using ATAs ${ }^{[34,35]}$ or amine dehydrogenases. ${ }^{[36-42]}$ In spite of these efforts, the biocatalytic synthesis of (3E)-4-arylbut-3-en-2-amines has received little attention, the activity of a commercial amine transaminase being low for the biotransamination of $(3 E)-4$ phenylbut-3-en-2-one towards optically active (3E)-4-phenylbut3-en-2-amine $(<30 \%) .{ }^{[43]}$

On the other hand, laccases display great potential for chemical synthesis but also pulp and paper industry applications. ${ }^{[44-46]}$ These redox enzymes are blue multicopper oxidases able to catalyse the oxidation of low molecular weight phenols at the expense of the reduction of molecular oxygen into water through a four-electron transference. ${ }^{[47]}$ However when attempting the oxidation of natural substrates, the enzyme requires the use of a chemical mediator, e.g. 2,2,6,6-tetramethylpiperidinoxyl radical (TEMPO). ${ }^{[48,49]}$ In this manner, the oxidation of diols, ${ }^{[50]}$ amino alcohols, ${ }^{\left[{ }^{[1]}\right.}$ profenols, ${ }^{[52]}$ benzylic ${ }^{[53,54]}$ and allylic alcohols ${ }^{[55]}$ has been fully exploited in our research group, in some cases being possible the development of sequential multienzymatic transformations by the proper modification of the reaction medium. These chemoenzymatic strategies include dynamic kinetic resolutions ${ }^{[52]}$ and deracemisation of alcohols in combination with alcohol dehydrogenases, ${ }^{[53]}$ the selective amination of benzylic alcohols by the use of amine transaminases ${ }^{[54]}$ or the redox isomerisation of allylic alcohols coupling the action of laccases with ene-reductases. ${ }^{[55]}$

Herein, we propose to extend the applicability of laccases to produce synthetically challenging optically active allylic amines via combination of a laccase-mediated oxidation of allylic alcohols and the subsequent stereoselective biotransamination of the resulting ketone intermediates using stereocomplementary ATAs (Scheme 1).

For internal use, please do not delete. Submitted_Manuscript 

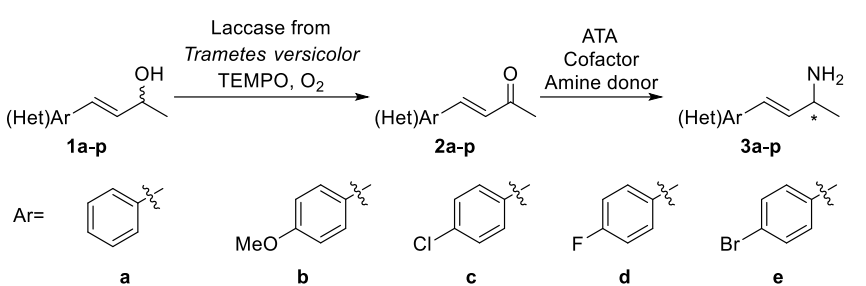<smiles>COc1cccc(I)c1</smiles>

HetAr=

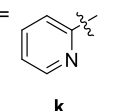<smiles>COc1ccccc1I</smiles><smiles>Fc1cccc(I)c1</smiles><smiles>[Y]c1ccccc1F</smiles>
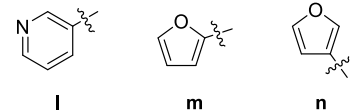

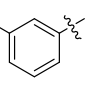

j

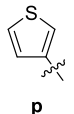

Scheme 1. Stereoselective chemoenzymatic amination of allylic alcohols 1a-p combining the laccase/TEMPO system with an amine transaminase.

\section{Results and Discussion}

Following the methodology reported by Gladkowski and coworkers, ${ }^{[56]}$ a series of (hetero)aromatic aldehydes were subjected to Claisen-Schmidt condensation with acetone under basic medium (Scheme S1), obtaining the corresponding unsaturated ketones $\mathbf{2 b}$ - $\mathbf{p}$ in good to very high isolated yields (54$94 \%$ ). Next, ketones 2a-p were chemically reduced using sodium borohydride to afford the desired racemic allylic alcohols 1a-p in $46-99 \%$ isolated yield.

At this point the study of the individual biooxidation and biotransamination steps were deeply analysed, trying first to find suitable conditions for the individual reactions, to later search for compatible conditions where both enzymes could act in a cascade or a sequential manner. Initially, (3E)-4-phenylbut-3-en-2-ol (1a) was selected as model substrate to study the applicability of commercially available laccase from Trametes versicolor ( $L T V$ ) in combination with different amounts of the oxy-radical TEMPO (10-33 mol\%, Table 1). The reactions were carried out under previously optimised conditions in our research group. ${ }^{[1,53]}$ This is, in a citrate buffer $50 \mathrm{mM} \mathrm{pH} 5$ with a $100 \mathrm{mM}$ substrate concentration at $30{ }^{\circ} \mathrm{C}$ and in an open-to-air tube to assure the oxygen presence. Interestingly, only a $7 \%$ conversion into the ketone 2a was observed with a high TEMPO concentration (33 mol\%, entry 1) in the buffer system. Therefore, to favour the solubility of the substrate, ${ }^{[51-55]}$ MTBE was employed as organic cosolvent $(20-50 \% \mathrm{v} / \mathrm{v}$, entries $2-5)$. Due to the low boiling point of MTBE, it evaporated from the medium after the first three hours leading to a monophasic system, and a complete conversion was attained when $50 \% \mathrm{v} / \mathrm{v}$ MTBE and $33 \mathrm{~mol} \%$ TEMPO were employed (entry 3), although the use of lower TEMPO loadings did not allow the reaction get to completion (entries 4 and 5). Even at prolonged times using $20 \mathrm{~mol} \%$ of TEMPO (94 and $98 \%$ conversion after 24 and $48 \mathrm{~h}$, respectively) and $10 \mathrm{~mol} \%$ of TEMPO (70 and $74 \%$ after 24 and $48 \mathrm{~h}$, respectively).

Table 1. Oxidation of 1a $(100 \mathrm{mM})$ with the LTV/TEMPO system in the presence of different amounts of TEMPO and MTBE as cosolvent.

\begin{tabular}{|c|c|c|c|}
\hline$\underbrace{1 \mathrm{a}}_{(100 \mathrm{mM})}$ & $\begin{array}{r}\text { Laccase from } T \\
\text { TEMPO (10 } \\
\text { Citrate buffe } \\
\text { MTBE } \\
30^{\circ} \\
\text { magne }\end{array}$ & $\begin{array}{l}\text { tes versicolor } \\
\text { nol\%), } \mathrm{O}_{2} \\
\mathrm{mM} \mathrm{pH} 5 \\
\mathrm{~m} \text { v/v) } \\
\mathrm{ih} \\
\mathrm{irring}\end{array}$ & $y$ \\
\hline Entry & TEMPO (mol\%) & MTBE (\% v/v) & $2 \mathrm{a}(\%)^{[a]}$ \\
\hline 1 & 33 & -.. & 7 \\
\hline 2 & 33 & 20 & 8 \\
\hline 3 & 33 & 50 & $>99$ \\
\hline 4 & 20 & 50 & 87 \\
\hline 5 & 10 & 50 & 64 \\
\hline
\end{tabular}

[a] Conversion values were measured by GC analyses.

The optimised reaction conditions found for 1a (entry 3 , Table 1) were then applied to the oxidation of the other allylic alcohols $\mathbf{1 b}$ p, gratifyingly finding excellent to complete conversions (>98\%, Table 2), independently on the position and the electronic character of the substitution at the phenyl ring, and also for various heteroaromatic derivatives such as pyridyl, furyl and thienyl. Satisfyingly, no by-products were detected in any case, demonstrating the mildness and selectivity of the chemoenzymatic system here proposed. 
Table 2. Oxidation of racemic allylic alcohols 1a-p (100 mM) with the laccase/TEMPO system using MTBE as cosolvent.

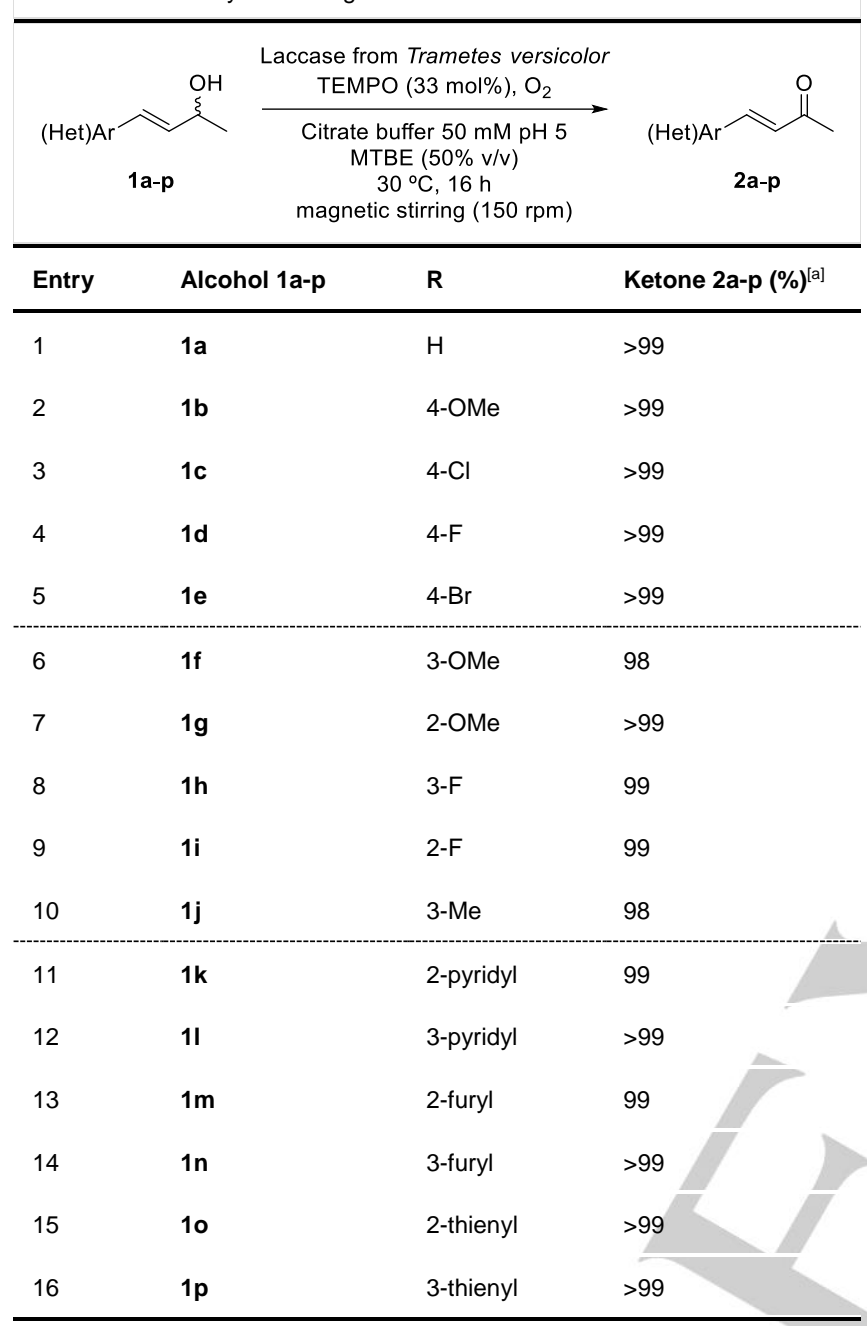

[a] Conversion values were measured by GC analyses.

At this point the biotransamination experiments of the $(3 E)-4$ (het)arylbut-3-en-2-ones 2a-p were assayed, in order to find adequate reaction conditions but also suitable amine transaminases (ATAs) for each substrate to later attempt the stereoselective amination of the racemic alcohols in a concurrent approach. PLP-dependent ATAs have been found as ideal biocatalysts for the transformation of prochiral and racemic ketones into optically active amines using a molar excess of an amine donor, generally isopropylamine or alanine. ${ }^{[57-61]}$ For simplicity, an initial assessment was developed using ketone $\mathbf{2 a}$ and commercially available $(R)$-selective ATA-024, that is known to accept isopropylamine as amine donor. Reaction parameters such as the amount of pyridoxal-5'-phosphate (PLP), ketone concentration, temperature and ATA loading were considered (Table 3).
Table 3. Biotransamination of ketone $2 \mathbf{a}$ using ATA-024 as biocatalyst and isopropylamine as amine donor.

\begin{tabular}{|c|c|c|c|c|c|}
\hline \multicolumn{2}{|c|}{$2 a$} & \multicolumn{2}{|c|}{$\begin{array}{c}\text { ATA-024 } \\
\text { Isopropylamine }(1.0 \mathrm{M}) \\
\text { PLP } \\
\text { KPi Buffer } 100 \mathrm{mM} \mathrm{pH} 7.5 \\
\text { DMSO }(2.5 \% \mathrm{v} / \mathrm{v}) \\
24 \mathrm{~h}, 250 \mathrm{rpm}\end{array}$} & \multicolumn{2}{|c|}{$(R)-\mathbf{3 a}$} \\
\hline Entry & [2a] $(\mathrm{mM})$ & [PLP] (mM) & $\mathrm{T}\left({ }^{\circ} \mathrm{C}\right)$ & $\begin{array}{l}\text { ATA-024 } \\
(\mathrm{mg} / \mathrm{mL})^{[\mathrm{a}]}\end{array}$ & $c(\%)^{[b]}$ \\
\hline 1 & 25 & 0.25 & 30 & 4 & 45 \\
\hline 2 & 25 & 0.5 & 30 & 4 & 46 \\
\hline 3 & 25 & 1.0 & 30 & 4 & 46 \\
\hline 4 & 10 & 0.25 & 30 & 4 & 56 \\
\hline 5 & 5 & 0.25 & 30 & 4 & 61 \\
\hline 6 & 10 & 0.25 & 30 & 8 & 56 \\
\hline 7 & 10 & 0.25 & 45 & 4 & 63 \\
\hline
\end{tabular}

[a] mg of lyophilised ATA-024 per mL of solvent. [b] Conversion values were measured by GC analyses.

The use of different cofactor amounts seemed to have not significant impact in the conversion when $25 \mathrm{mM}$ of ketone $\mathbf{2 a}$ was used (entries 1-3, 45-46\% conversion), while higher conversions were reached at low substrate concentrations (5 and $10 \mathrm{mM}$, entries 4 and 5), although there was no change when using more enzyme loading (entry 6). For practical applications, the best conditions were found when increasing the temperature to $45 \stackrel{\circ}{\circ}$ reaching a promising $63 \%$ conversion at $10 \mathrm{mM}$ ketone concentration (entry 7).

From this point, exhaustive screenings using ATAs overexpressed in E. coli cells and later lyophilised (Chromobacterium violaceum, ${ }^{[62]}$ Arthrobacter citreus, ${ }^{[63]}$ Arthrobacter species ${ }^{[64-66]}$ and its evolved mutant ArRmut11 ${ }^{[67]}$ ) and semipurified commercially available ATAs, also in lyophilised form, were developed for the sixteen unsaturated ketones considered in this study, and for a clear understanding all the results in terms of conversion and enantiomeric excess values have been included in the Electronic Supporting Information. The best results are highlighted in Table 4, observing low to very high conversion values (15-89\%) and excellent selectivities (>97\% ee). Remarkably the preparation of both amine enantiomers was possible depending on the ATA selectivity. Especially $(R)$ selective ATA-024, ATA-033 and ATA-415, and (S)-selective ATA-254, ATA-256 and ATA-260 enzymes proved to be the most efficient catalysts in these transformations. 
Table 4. Biotransamination of ketones 2a-p using amine transaminases and isopropylamine as amine donor.

\begin{tabular}{|c|c|c|c|c|c|}
\hline \multicolumn{2}{|c|}{$\begin{array}{c}\text { 2a-p } \\
(10 \mathrm{mM})\end{array}$} & \multicolumn{2}{|c|}{$\begin{array}{c}\text { Amine transaminase } \\
\text { Isopropylamine }(1.0 \mathrm{M}) \\
\text { PLP }(1 \mathrm{mM}) \\
\mathrm{KPi} \text { Buffer } 100 \mathrm{mM} \mathrm{pH} 7.5 \\
\text { DMSO }(2.5 \% \mathrm{v} / \mathrm{v}) \\
45^{\circ} \mathrm{C}, 24 \mathrm{~h}, 250 \mathrm{rpm}\end{array}$} & \multicolumn{2}{|r|}{ 3a-p } \\
\hline Entry & Ketone & $\mathbf{R}$ & Enzyme & $\boldsymbol{c}(\%)^{[\mathrm{a}]}$ & ee 3a-p (\%) ${ }^{[b]}$ \\
\hline 1 & $2 a$ & $\mathrm{H}$ & ATA-033 & 56 & $99(R)$ \\
\hline 2 & $2 a$ & $\mathrm{H}$ & ATA-256 & 57 & $>99(S)$ \\
\hline 3 & $2 b$ & 4-OMe & ATA-025 & 42 & $>99(R)$ \\
\hline 4 & $2 b$ & 4-OMe & ATA-254 & 39 & $>99(S)$ \\
\hline 5 & $2 c$ & $4-\mathrm{Cl}$ & ATA-415 & 45 & $>99(R)$ \\
\hline 6 & $2 c$ & $4-\mathrm{Cl}$ & ATA-256 & 42 & $99(S)$ \\
\hline 7 & $2 d$ & $4-\mathrm{F}$ & ATA-033 & 50 & $>99(R)$ \\
\hline 8 & $2 d$ & $4-\mathrm{F}$ & ATA-254 & 49 & $>99(S)$ \\
\hline 9 & $2 e$ & $4-\mathrm{Br}$ & ATA-033 & 38 & $>99(R)$ \\
\hline 10 & $2 e$ & $4-\mathrm{Br}$ & ATA-254 & 43 & $>99(S)$ \\
\hline 11 & $2 f$ & 3-OMe & ATA-024 & 34 & $>99(R)$ \\
\hline 12 & $2 f$ & 3-OMe & ATA-256 & 38 & $99(S)$ \\
\hline 13 & $2 g$ & 2-OMe & ATA-415 & 15 & $99(R)$ \\
\hline 14 & $2 g$ & 2-OMe & TA-P1-G06 & 23 & $99(S)$ \\
\hline 15 & $2 \mathrm{~h}$ & $3-F$ & ATA-025 & 56 & $>99(R)$ \\
\hline 16 & $2 \mathrm{~h}$ & $3-F$ & ATA-254 & 59 & $>99(S)$ \\
\hline 17 & $2 \mathbf{i}$ & $2-\mathrm{F}$ & ATA-033 & 77 & $>99(R)$ \\
\hline 18 & $2 \mathbf{i}$ & $2-\mathrm{F}$ & ATA-256 & 76 & $>99(S)$ \\
\hline 19 & $2 j$ & 3-Me & ATA-025 & 32 & $>99(R)$ \\
\hline 20 & $2 \mathbf{j}$ & 3-Me & ATA-256 & 39 & $>99(S)$ \\
\hline 21 & $2 k$ & 2-pyridyl & ATA-415 & 59 & $>99(R)$ \\
\hline 22 & $2 k$ & 2-pyridyl & TA-P1-G06 & 89 & $>99(S)$ \\
\hline 23 & 21 & 3-pyridyl & ATA-024 & 82 & $>99(R)$ \\
\hline 24 & 21 & 3-pyridyl & ATA-260 & 76 & $99(S)$ \\
\hline 25 & $2 m$ & 2-furyl & ATA-024 & 56 & $>99(R)$ \\
\hline 26 & $2 m$ & 2-furyl & TA-P1-A06 & 57 & $>99(S)$ \\
\hline 27 & $2 n$ & 3-furyl & ATA-033 & 56 & $>99(R)$ \\
\hline 28 & $2 n$ & 3-furyl & ATA-260 & 60 & $98(S)$ \\
\hline 29 & 20 & 2-thienyl & ATA-024 & 57 & $>99(R)$ \\
\hline 30 & 20 & 2-thienyl & ATA-260 & 58 & $99(S)$ \\
\hline 31 & $2 p$ & 3-thienyl & ATA-024 & 63 & $>99(R)$ \\
\hline 32 & $2 p$ & 3-thienyl & ATA-260 & 63 & $99(S)$ \\
\hline
\end{tabular}

[a] Conversion values were measured by GC analyses. [b] Enantiomeric excess were measured by GC analyses after derivatisation of the corresponding amines with acetic anhydride.
Finally, the two-step sequential process was attempted, so after the laccase-catalysed oxidation, optimal conditions in terms of $\mathrm{pH}$, substrate concentration and temperature for the ATAs were provided in order to make feasible the biotransamination reaction. Thus, the $\mathrm{pH}$ of the solution was adjusted to a value of 7.5 diluting accordingly the solution until a $10 \mathrm{mM}$ ketone intermediate concentration, $2.5 \%$ DMSO was added to solubilise the reactants and the temperature was increased up to $45^{\circ} \mathrm{C}$. In this manner, the 16 amine enantiomer pairs of $\mathbf{3 a - p}$ were obtained in high to excellent enantiomeric excess values (>93\%). For the isolation of the optically active products, a simple liquid-liquid extraction protocol was required for allylic amines $3 a-j$ and $3 \mathrm{~m}-\mathbf{p}$, while for the pyridyl compounds $\mathbf{3} \mathbf{k}$ and $\mathbf{3} \mathbf{l}$ a column chromatography was necessary to isolate them in a pure form $(4.1-10.5 \mathrm{mg}, 29-81 \%$ isolated yield, Scheme 2). It must be mentioned that when the scale-up of the processes was achieved, the use of MeCN as cosolvent was applied as it simplified the isolation processes through liquid-liquid extraction, providing higher amine yields.

\section{Conclusions}

The design of chemoenzymatic and multienzymatic strategies for the synthesis of optically active compounds is one of the most demanding task pursuits nowadays in organic synthesis. Herein, a sequential two-step synthetic approach has been described for the synthesis of a series of optically active (3E)-4-(het)arylbut-3en-2-amines starting from the corresponding racemic allylic alcohols. Individual biotransformations were studied and optimised, finding suitable conditions for the chemoselective oxidation of (3E)-4-(het)arylbut-3-en-2-ols, and the biotransamination of the corresponding $(3 E)$-4-arylbut-3-en-2ones.

The catalytic system composed by the laccase from Trametes versicolor and the chemical mediator TEMPO (33 mol\%) has selectively oxidised 16 racemic allylic alcohols with excellent conversion (>98\%) after $16 \mathrm{~h}$ at $30 \stackrel{\circ}{\circ}$ and using a $100 \mathrm{mM}$ alcohol concentration, isolating the corresponding ketones with excellent purity just after a liquid-liquid extraction protocol. After amine transaminase screening, pairs of enzymes with opposite selectivity were found to give access to the corresponding optically active allylic amines in enantiopure form.

A sequential protocol employing both enzymatic methods was possible by simple changing the $\mathrm{pH}$ from 5.0 to 7.5 and diluting the ketone intermediate concentration to $10 \mathrm{mM}$, so after addition of the amine donor (isopropylamine) and the enzyme cofactor (PLP), a wide panel of optically active (3E)-4-arylbut-3-en-2amines were obtained in $>94 \%$ ee after $24 \mathrm{~h}$ at $45^{\circ} \mathrm{C}$ in moderate to good isolated yields (29-81\%) after a simple extraction protocol, except for pyridyl-derived amines that required an additional column chromatography purification. 


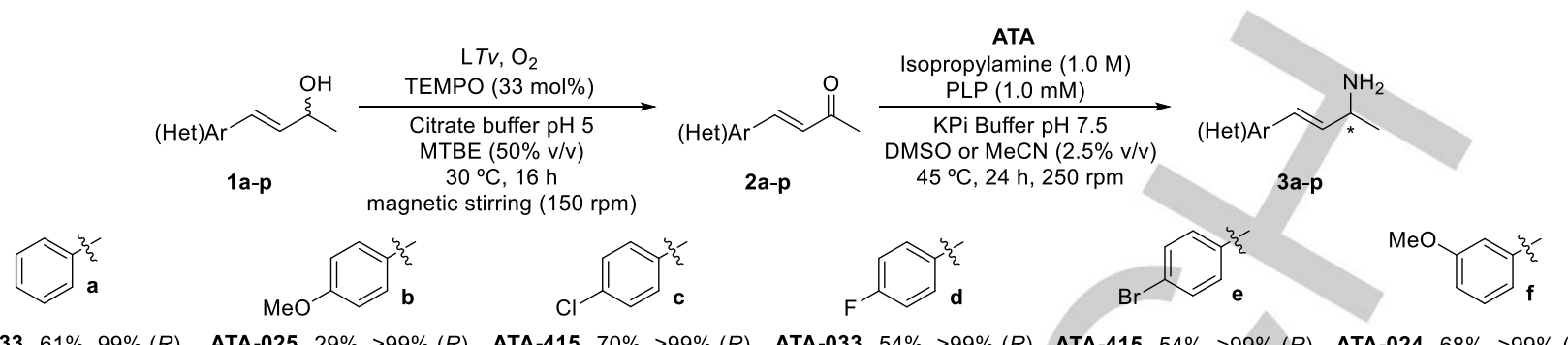

ATA- $033,61 \%, 99 \%(R) \quad$ ATA-025, 29\%, >99\% $(R) \quad$ ATA-415, 70\%, >99\% $(R) \quad$ ATA-033, 54\%, >99\% $(R) \quad$ ATA-415, 54\%, >99\% $(R) \quad$ ATA-024, 68\%, >99\% $(R)$ ATA-256, 70\%, 97\% (S) ATA-254, 42\%, >99\% (S) ATA-256, 75\%, 94\% (S)<smiles>COc1ccccc1C</smiles>

ATA-415, $48 \%, 99 \%(R)$ TA-P1-G06, 49\%, 99\% (S)

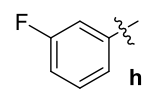

ATA-025, 70\%, 95\% (R) ATA-254, 75\%, 94\% (S)

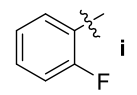

ATA-033, 72\%, >99\% (R) ATA-256, 58\%, 99\% (S)

ATA-260, 51\%, 95\% (S)

ATA-256, 59\%, >99\% (S)

ATA-256, $61 \%, 99 \%(S)$

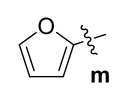

ATA-024, 64\%, >99\% $(R)$ TA-P1-A06, 53\%, >99\% (S)

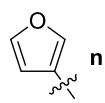

ATA-033, $52 \%,>99 \%(R)$ ATA-260, $57 \%, 98 \%(S)$
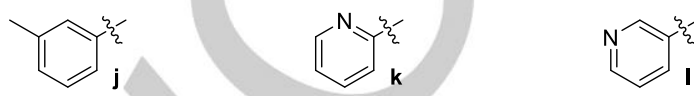

ATA- $025,69 \%,>99 \%(R) \quad$ ATA-415, 68\%, 99\% $(R) \quad$ ATA-025, 70\%, >99\% $(R)$ ATA-256, 63\%, >99\% (S) TA-P1-G06, 81\%, >99\% (S) ATA-260, 72\%, 99\%(S)

Scheme 2. Stereoselective amination of racemic alcohols 1a-p through a sequential strategy. Isolated yields are shown after a liquid-liquid extraction protocol, requiring $\mathbf{3 k}$ and $\mathbf{3} \mathbf{I}$ an additional column chromatography purification.

\section{Experimental Section}

\section{Material and methods}

Ketone 2a was acquired from Sigma-Aldrich. Laccase from Trametes versicolor (LTv, $0.66 \mathrm{U} / \mathrm{mg}$ ) and pyridoxal 5'-phosphate (PLP) were purchased from Sigma-Aldrich. Codex Transaminase ATA Screening Kit (ATASK-000250) was purchased from Codexis Inc. The lot numbers of the more active commercially available ATAs are: D101186 (ATA-024), 0907A (ATA-025), D15042 (ATA-033), PF282 (ATA-254), 01 (ATA-256), D11125 (ATA-260), D11130 (ATA-415), FER090326 (TA-P1-A06) and D15046 (TA-P1-G06). Lyophilised ATAs overexpressed in E. coli were obtained as previously reported in the literature. ${ }^{[62-67]}$ All other reagents and solvents were obtained from Sigma-Aldrich or Acros and used as received.

Sequential reactions were performed in test tubes $[(19 \times 130 \times 3) \mathrm{mm}]$ and centrifuge tubes $[(17 \times 118 \times 15) \mathrm{mm}]$. The oxidation step mediated by the laccase/TEMPO catalytic system was performed in an open-to-air test tube using magnetic stirring, while for the subsequent transamination step, the reaction media was transferred to the centrifuge tube, and shaken at 250 rpm and $45^{\circ} \mathrm{C}$ for the required time.

NMR spectra were recorded on a Bruker AV300 MHz spectrometer. All chemical shifts $(\delta)$ are given in parts per million (ppm) and referenced to the residual solvent signal as internal standard. IR spectra were recorded on a Bruker ALPHA spectrophotometer on $\mathrm{NaCl}$ pellets. High resolution mass spectra (HRMS) were obtained in a Bruker Daltonics spectrometer using the ESI-TOF positive mode. Measurement of the optical rotation was carried out at $590 \mathrm{~nm}$ in a PerkinElmer 241 polarimeter. Thin layer chromatrographies (TLCs) were conducted with Merck Silica Gel 60 F254 precoated plates and visualised with UV and potassium permanganate stain. Column chromatographies were performed using Merck Silica Gel 60 (230-400 mesh).

Gas chromatrography (GC) analyses were performed on Agilent HP6890 and Agilent HP7820A gas chromatograph apparatus equipped with a FID detector for the measurement of conversion and enantiomeric excess values. High performance liquid chromatography (HPLC) analyses were carried out in a Hewlett Packard 1100 chromatograph UV detector at a 210 $\mathrm{nm}$ wavelength for the measurement of enantiomeric excess values. Details of analytical methods, retention times and chromatograms have been included in the Electronic Supporting Information.

\section{Typical procedure for the synthesis of ketones $2 b-p$}

Ketones 2b-p were synthesised following the procedure described by Gładkowski et al. for ketone $\mathbf{2 a}$ as follows:[56] A solution of the corresponding aldehyde $(3.3 \mathrm{mmol})$ in acetone $(1 \mathrm{~mL})$ and water $(0.1 \mathrm{~mL})$ was placed in a water bath. Then, a $10 \% \mathrm{NaOH}$ aqueous solution $(0.1 \mathrm{~mL})$ was slowly added. The reaction mixture was stirred overnight at room temperature and acidified after this time with a $\mathrm{HCl} 2 \mathrm{M}$ aqueous solution to $\mathrm{pH}$ 2. The product was extracted with $\mathrm{CH}_{2} \mathrm{Cl}_{2}(3 \times 15 \mathrm{~mL})$ and the combined organic phases dried over anhydrous $\mathrm{Na}_{2} \mathrm{SO}_{4}$, filtered and the solvent evaporated under reduced pressure. The reaction crude was purified by column chromatography on silica gel (25\% EtOAc/hexane except $83 \%$ EtOAc/hexane for pyridyl substrates), yielding the corresponding ketones 2 b-p (54-94\% yield).

(E)-4-Phenylbut-3-en-2-one (2a) Yellow solid. $R_{f}$ (25\% EtOAc/hexane): 0.58. Mp: $38-40 \stackrel{\circ}{ } \mathrm{C}$. IR ( $\mathrm{NaCl}): 3060,3028,3003,1668,1610,1359,1279$,

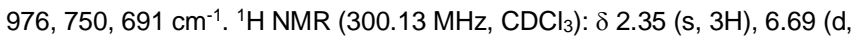
$\left.{ }^{3} \mathrm{~J}_{\mathrm{HH}}=16.3 \mathrm{~Hz}, 1 \mathrm{H}\right), 7.34-7.39(\mathrm{~m}, 3 \mathrm{H}), 7.46-7.53(\mathrm{~m}, 3 \mathrm{H}) \mathrm{ppm} .{ }^{13} \mathrm{C} N M R$ (75.5 MHz, $\left.\mathrm{CDCl}_{3}\right): \delta 27.5\left(\mathrm{CH}_{3}\right), 127.1(\mathrm{CH}), 128.3(2 \mathrm{CH}), 129.0(2 \mathrm{CH})$, $130.5(\mathrm{CH}), 134.4(\mathrm{C}), 143.4(\mathrm{CH}), 198.4(\mathrm{C}) \mathrm{ppm}$. HRMS $\left(\mathrm{ESI}^{+}, \mathrm{m} / \mathrm{z}\right)$ : calcd for $\left(\mathrm{C}_{10} \mathrm{H}_{11} \mathrm{O}\right)^{+}(\mathrm{M}+\mathrm{H})^{+}$147.0804, found: 147.0803 .

(E)-4-(4-Methoxyphenyl)but-3-en-2-one (2b). Pale yellow solid (512 mg,

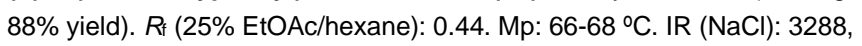
3048, 2941, 2916, 2844, 2774, 2241, 1896, 1683, 1601, 1512, 1251, 989, $854 \mathrm{~cm}^{-1} .{ }^{1} \mathrm{H}$ NMR $\left(300.13 \mathrm{MHz}, \mathrm{CDCl}_{3}\right): \delta 2.29(\mathrm{~s}, 3 \mathrm{H}), 3.76(\mathrm{~s}, 3 \mathrm{H}), 6.54$ $\left(\mathrm{d},{ }^{3} \mathrm{~J}_{\mathrm{HH}}=16.3 \mathrm{~Hz}, 1 \mathrm{H}\right), 6.82-6.88(\mathrm{~m}, 2 \mathrm{H}), 7.38-7.44(\mathrm{~m}, 3 \mathrm{H}) \mathrm{ppm} .{ }^{13} \mathrm{C}$ NMR (75.5 MHz, CDCl 3$): \delta 27.5\left(\mathrm{CH}_{3}\right), 55.5\left(\mathrm{CH}_{3}\right), 114.6(2 \mathrm{CH}), 125.1$

For internal use, please do not delete. Submitted_Manuscript 
$(\mathrm{CH}), 127.2(\mathrm{C}), 130.1(2 \mathrm{CH}), 143.4(\mathrm{CH}), 161.7(\mathrm{C}), 198.5(\mathrm{C}) \mathrm{ppm}$. HRMS $\left(\mathrm{ESI}^{+}, \mathrm{m} / \mathrm{z}\right)$ : calcd for $\left(\mathrm{C}_{11} \mathrm{H}_{13} \mathrm{O}_{2}\right)^{+}(\mathrm{M}+\mathrm{H})^{+}$177.0910, found: 177.0917 .

(E)-4-(4-Chlorophenyl)but-3-en-2-one (2c). Pale yellow solid (382 mg, $64 \%$ yield). $R_{\mathrm{f}}\left(25 \%\right.$ EtOAc/hexane): 0.56 . Mp: $56-57^{\circ} \mathrm{C}$. IR ( $\left.\mathrm{NaCl}\right): 3286$, 3044, 3021, 2972, 2922, 1946, 1661, 1092, 979, $810 \mathrm{~cm}^{-1} .{ }^{1} \mathrm{H}$ NMR $\left(300.13 \mathrm{MHz}, \mathrm{CDCl}_{3}\right): \delta 2.31(\mathrm{~s}, 3 \mathrm{H}), 6.62\left(\mathrm{~d},{ }^{3} \mathrm{JHH}_{\mathrm{HH}}=16.3 \mathrm{~Hz}, 1 \mathrm{H}\right), 7.27-$ $7.32(\mathrm{~m}, 2 \mathrm{H}), 7.36-7.43(\mathrm{~m}, 3 \mathrm{H}) \mathrm{ppm} .{ }^{13} \mathrm{C}$ NMR $\left(75.5 \mathrm{MHz}, \mathrm{CDCl}_{3}\right): \delta 27.6$ $\left(\mathrm{CH}_{3}\right), 127.4(\mathrm{CH}), 129.2(2 \mathrm{CH}), 129.4(2 \mathrm{CH}), 132.9(\mathrm{C}), 136.3(\mathrm{C}), 141.8$ $(\mathrm{CH}), 198.0$ (C) ppm. HRMS $\left(\mathrm{ESI}^{+}, \mathrm{m} / \mathrm{z}\right)$ : calcd for $\left(\mathrm{C}_{10} \mathrm{H}_{10} \mathrm{ClO}\right)^{+}(\mathrm{M}+\mathrm{H})^{+}$ 181.0415, found: 181.0413 .

(E)-4-(4-Fluorophenyl)but-3-en-2-one (2d). Pale yellow solid (293 mg, $54 \%$ yield). $R_{\mathrm{f}}\left(25 \%\right.$ EtOAc/hexane): 0.54 . Mp: $31-33^{\circ} \mathrm{C}$. IR ( NaCl): 3072 , $3048,3021,2923,2009,1897,1668,1599,1509,1231,977,818 \mathrm{~cm}^{-1} .{ }^{1} \mathrm{H}$ $\operatorname{NMR}\left(300.13 \mathrm{MHz}, \mathrm{CDCl}_{3}\right): \delta 2.23(\mathrm{~s}, 3 \mathrm{H}), 6.50\left(\mathrm{~d},{ }^{3} \mathrm{JHH}_{\mathrm{H}}=16.3 \mathrm{~Hz}, 1 \mathrm{H}\right)$, 6.88-6.99 (m, 2H), 7.29-7.44 (m, 3H). ${ }^{13} \mathrm{C}$ NMR $\left(75.5 \mathrm{MHz}, \mathrm{CDCl}_{3}\right): \delta 27.2$ $\left(\mathrm{CH}_{3}\right), 115.8(\mathrm{~d}, J=22.0 \mathrm{~Hz}, 2 \mathrm{CH}), 126.6(\mathrm{~d}, J=2.2 \mathrm{~Hz}, \mathrm{CH}), 130.0(\mathrm{~d}, J$ $=8.5 \mathrm{~Hz}, 2 \mathrm{CH}), 130.5(\mathrm{~d}, J=3.2 \mathrm{~Hz}, \mathrm{C}), 141.7(\mathrm{CH}), 163.7$ (d, $J=251.3$ $\mathrm{Hz}, \mathrm{C}), 197.8$ (C) ppm. ${ }^{19} \mathrm{~F} \mathrm{NMR}\left(282 \mathrm{MHz}, \mathrm{CDCl}_{3}\right): \delta-109.2 \mathrm{ppm}$. HRMS $(\mathrm{ESI}+\mathrm{m} / \mathrm{z})$ : calcd for $\left(\mathrm{C}_{10} \mathrm{H}_{10} \mathrm{FO}\right)^{+}(\mathrm{M}+\mathrm{H})^{+} 165.0710$, found: 165.0696 .

(E)-4-(4-Bromophenyl)but-3-en-2-one (2e). White solid (424 mg, 57\%

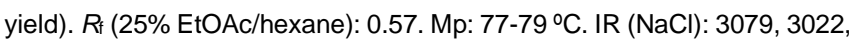
2924, 1912, 1657, 1584, 1262, 978, $806 \mathrm{~cm}^{-1} .{ }^{1} \mathrm{H}$ NMR $(300.13 \mathrm{MHz}$, $\left.\mathrm{CDCl}_{3}\right): \delta 2.30(\mathrm{~s}, 3 \mathrm{H}), 6.61\left(\mathrm{~d},{ }^{3} \mathrm{JHH}_{\mathrm{HH}}=16.3 \mathrm{~Hz}, 1 \mathrm{H}\right), 7.28-7.39(\mathrm{~m}, 3 \mathrm{H})$, 7.40-7.46 (m, 2H) ppm. $\left.{ }^{13} \mathrm{C} \mathrm{NMR} \mathrm{(75.5} \mathrm{MHz,} \mathrm{CDCl}_{3}\right): \delta 27.6\left(\mathrm{CH}_{3}\right), 124.6$ (C), $127.4(\mathrm{CH}), 129.5(2 \mathrm{CH}), 132.1(2 \mathrm{CH}), 133.3(\mathrm{C}), 141.8(\mathrm{CH}), 197.9$ (C) ppm. HRMS $\left(\mathrm{ESI}^{+}, \mathrm{m} / \mathrm{z}\right)$ : calcd for $\left(\mathrm{C}_{10} \mathrm{H}_{10} \mathrm{BrO}\right)^{+}(\mathrm{M}+\mathrm{H})^{+} 224.9910$, found: 224.9920.

(E)-4-(3-Methoxyphenyl)but-3-en-2-one (2f). Yellow liquid (460 mg, 79\% yield). $R_{\mathrm{f}}(25 \%$ EtOAc/hexane): 0.48. IR ( $\mathrm{NaCl}): 3370,3003,2961,2942$, 2837, 2205, 2072, 2034, 1984, 1933, 1690, 1669, 1359, 1170, 1046, 978, $780,752,687 \mathrm{~cm}^{-1} .{ }^{1} \mathrm{H}$ NMR $\left(300.13 \mathrm{MHz}, \mathrm{CDCl}_{3}\right): \delta 2.38(\mathrm{~s}, 3 \mathrm{H}), 3.83(\mathrm{~s}$, $3 \mathrm{H}), 6.70\left(\mathrm{~d},{ }^{3} \mathrm{JHH}_{\mathrm{HH}}=16.3 \mathrm{~Hz}, 1 \mathrm{H}\right), 6.95\left(\mathrm{ddd},{ }^{3} \mathrm{JHH}_{\mathrm{HH}}=8.2,{ }^{4} \mathrm{JHH}_{\mathrm{HH}}=2.6,{ }^{4} \mathrm{JHH}=\right.$ $1.0 \mathrm{~Hz}, 1 \mathrm{H}), 7.06$ (apparent t, $\left.{ }^{4} \mathrm{JHH}=2.6 \mathrm{~Hz}, 1 \mathrm{H}\right), 7.13\left(\mathrm{~d},{ }^{3} \mathrm{JHH}=7.7 \mathrm{~Hz}, 1 \mathrm{H}\right)$, 7.31 (apparent t, $\left.{ }^{3} \mathrm{JHH}_{\mathrm{HH}}=7.9 \mathrm{~Hz}, 1 \mathrm{H}\right), 7.47\left(\mathrm{~d},{ }^{3} \mathrm{JHH}=16.3 \mathrm{~Hz}, 1 \mathrm{H}\right) \mathrm{ppm} .{ }^{13} \mathrm{C}$ $\operatorname{NMR}\left(75.5 \mathrm{MHz}, \mathrm{CDCl}_{3}\right): \delta 26.8\left(\mathrm{CH}_{3}\right), 54.6\left(\mathrm{CH}_{3}\right), 112.7(\mathrm{CH}), 115.8(\mathrm{CH})$, $120.4(\mathrm{CH}), 126.8(\mathrm{CH}), 129.4(\mathrm{CH}), 135.3(\mathrm{C}), 142.7(\mathrm{CH}), 159.4(\mathrm{C})$, $197.6(\mathrm{C}) \mathrm{ppm}$. HRMS $\left(\mathrm{ESI}^{+}, \mathrm{m} / \mathrm{z}\right)$ : calcd for $\left(\mathrm{C}_{11} \mathrm{H}_{13} \mathrm{O}_{2}\right)^{+}(\mathrm{M}+\mathrm{H})^{+}$177.0910, found: 177.0914 .

(E)-4-(2-Methoxyphenyl)but-3-en-2-one (2g). Pale yellow solid (425 mg, $73 \%$ yield). $R_{\mathrm{f}}\left(25 \%\right.$ EtOAc/hexane): $0.50 . \mathrm{Mp}: 49-51^{\circ} \mathrm{C}$. IR (NaCl): 3003 , 2940, 2888, 2838, 1666, 1598, 1488, 1466, 1246, 1026, $754 \mathrm{~cm}^{-1} .{ }^{1} \mathrm{H}$ NMR $\left(300.13 \mathrm{MHz}, \mathrm{CDCl}_{3}\right): \delta 2.15(\mathrm{~s}, 3 \mathrm{H}), 3.63(\mathrm{~s}, 3 \mathrm{H}), 6.54\left(\mathrm{~d},{ }^{3} \mathrm{JHH}_{\mathrm{H}}=16.5 \mathrm{~Hz}\right.$, $1 \mathrm{H}), 6.69\left(\mathrm{dd},{ }^{3} \mathrm{JHH}_{\mathrm{HH}}=8.5,{ }^{4} \mathrm{~J}_{\mathrm{HH}}=0.8 \mathrm{~Hz}, 1 \mathrm{H}\right), 6.74$ (apparent td, ${ }^{3} \mathrm{JHH}_{\mathrm{HH}}=7.4$, $\left.{ }^{4} \mathrm{JHH}_{\mathrm{HH}}=0.8 \mathrm{~Hz}, 1 \mathrm{H}\right), 7.14\left(\mathrm{ddd},{ }^{3} \mathrm{JHH}_{\mathrm{HH}}=8.3,{ }^{3} \mathrm{JHH}_{\mathrm{HH}}=7.4,{ }^{4} \mathrm{JHH}_{\mathrm{HH}}=1.7 \mathrm{~Hz}, 1 \mathrm{H}\right)$, $7.30\left(\mathrm{dd},{ }^{3} \mathrm{JHH}_{\mathrm{HH}}=7.8,{ }^{4} \mathrm{JHH}_{\mathrm{HH}}=1.7 \mathrm{~Hz}, 1 \mathrm{H}\right), 7.68\left(\mathrm{~d},{ }^{3} \mathrm{JHH}_{\mathrm{HH}}=16.5 \mathrm{~Hz}, 1 \mathrm{H}\right) \mathrm{ppm}$. ${ }^{13} \mathrm{C} \mathrm{NMR}\left(75.5 \mathrm{MHz}, \mathrm{CDCl}_{3}\right): \delta 26.7\left(\mathrm{CH}_{3}\right), 54.9\left(\mathrm{CH}_{3}\right), 110.7(\mathrm{CH}), 120.3$ $(\mathrm{CH}), 122.7(\mathrm{C}), 127.0(\mathrm{CH}), 127.7(\mathrm{CH}), 131.4(\mathrm{CH}), 138.0(\mathrm{CH}), 157.8$ (C), 198.1 (C) ppm. HRMS (ESl+, m/z): calcd for $\left(\mathrm{C}_{11} \mathrm{H}_{13} \mathrm{O}_{2}\right)^{+}(\mathrm{M}+\mathrm{H})^{+}$ 177.0910, found: 177.0915 .

(E)-4-(3-Fluorophenyl)but-3-en-2-one (2h). Pale yellow oil (309 mg, 57\% yield). $R_{\mathrm{f}}(25 \% \mathrm{EtOAc} / \mathrm{hexane}): 0.57$. IR ( $\left.\mathrm{NaCl}\right): 3066,3043,3006,2922$, $1944,1873,1804,1672,1615,1583,1439,1360,1259,979,783,682 \mathrm{~cm}$ 1. ${ }^{1} \mathrm{H}$ NMR $\left(300.13 \mathrm{MHz}, \mathrm{CDCl}_{3}\right): \delta 2.31(\mathrm{~s}, 3 \mathrm{H}), 6.63\left(\mathrm{~d},{ }^{3} \mathrm{JHH}_{\mathrm{HH}}=16.3 \mathrm{~Hz}\right.$, $1 \mathrm{H}), 6.97-7.06(\mathrm{~m}, 1 \mathrm{H})$, 7.13-7.19 $(\mathrm{m}, 1 \mathrm{H}), 7.21-7.34(\mathrm{~m}, 2 \mathrm{H}), 7.39\left(\mathrm{~d},{ }^{3} \mathrm{JHH}_{\mathrm{H}}\right.$ $=16.3 \mathrm{~Hz}, 1 \mathrm{H}) \mathrm{ppm} .{ }^{13} \mathrm{C} \mathrm{NMR}\left(75.5 \mathrm{MHz}, \mathrm{CDCl}_{3}\right): \delta 27.6\left(\mathrm{CH}_{3}\right), 114.3(\mathrm{~d}$, $J=21.8 \mathrm{~Hz}, \mathrm{CH}), 117.2(\mathrm{~d}, J=21.4 \mathrm{~Hz}, \mathrm{CH}), 124.2(\mathrm{~d}, J=2.7 \mathrm{~Hz}, \mathrm{CH})$,
$128.1(\mathrm{CH}), 130.5$ (d, J = 8.4 Hz, CH), 136.7 (d, $J=7.8 \mathrm{~Hz}, \mathrm{C}), 141.7$ (d, $J$ $=2.7 \mathrm{~Hz}, \mathrm{CH}), 162.9$ (d, $J=246.8 \mathrm{~Hz}, \mathrm{C}), 198.0$ (C) ppm. ${ }^{19} \mathrm{~F}$ NMR $(282$ $\left.\mathrm{MHz}, \mathrm{CDCl}_{3}\right): \delta-112.4 \mathrm{ppm}$. HRMS $\left(\mathrm{ESI}^{+}, \mathrm{m} / \mathrm{z}\right)$ : calcd for $\left(\mathrm{C}_{10} \mathrm{H}_{10} \mathrm{FO}\right)^{+}$ $(\mathrm{M}+\mathrm{H})^{+}$165.0710, found: 165.0707 .

(E)-4-(2-Fluorophenyl)but-3-en-2-one (2i). White solid (326 mg, 60\% yield). $R_{\mathrm{f}}(25 \%$ EtOAc/hexane): 0.59. Mp: 41-42 ㅇ. IR (NaCl): 3105,3040 , 3012, 2924, 1943, 1816, 1669, 1645, 1487, 1465, 1365, 1228, 1098, 974, $762 \mathrm{~cm}^{-1} .{ }^{1} \mathrm{H}$ NMR $\left(300.13 \mathrm{MHz}, \mathrm{CDCl}_{3}\right): \delta 2.31(\mathrm{~s}, 3 \mathrm{H}), 6.70\left(\mathrm{~d},{ }^{3} \mathrm{JHH}_{\mathrm{HH}}=\right.$ $16.5 \mathrm{~Hz}, 1 \mathrm{H}$ ), 7.02 (ddd, $J=10.7, J=8.2, J=1.1 \mathrm{~Hz}, 1 \mathrm{H}$ ), 7.10 (td, $J=7.6$, $J=1.1 \mathrm{~Hz}, 1 \mathrm{H}), 7.25-7.33(\mathrm{~m}, 1 \mathrm{H}), 7.48(\mathrm{td}, J=7.6, J=1.8 \mathrm{~Hz}, 1 \mathrm{H}), 7.59$ $\left(\mathrm{d},{ }^{3} \mathrm{JHH}_{\mathrm{HH}}=16.5 \mathrm{~Hz}, 1 \mathrm{H}\right) \mathrm{ppm} .{ }^{13} \mathrm{C} \mathrm{NMR}\left(75.5 \mathrm{MHz}, \mathrm{CDCl}_{3}\right): \delta 27.4\left(\mathrm{CH}_{3}\right)$, $116.1(\mathrm{~d}, J=21.9 \mathrm{~Hz}, \mathrm{CH}), 122.4(\mathrm{~d}, J=11.4 \mathrm{~Hz}, \mathrm{C}), 124.5(\mathrm{~d}, J=3.6 \mathrm{~Hz}$, $\mathrm{CH}), 128.6(\mathrm{~d}, J=3.0 \mathrm{~Hz}, \mathrm{CH}), 129.1(\mathrm{~d}, J=5.4 \mathrm{~Hz}, \mathrm{CH}), 131.9(\mathrm{~d}, J=8.7$ $\mathrm{Hz}, \mathrm{CH}$ ), 135.5 (d, J=3.5 Hz, CH), 161.2 (d, $J=253.9 \mathrm{~Hz}, \mathrm{C}$ ), 198.2 (C) ppm. ${ }^{19} \mathrm{~F} \mathrm{NMR}\left(282 \mathrm{MHz}, \mathrm{CDCl}_{3}\right): \delta-114.8 \mathrm{ppm}$. HRMS $\left(\mathrm{ESI}^{+}, \mathrm{m} / \mathrm{z}\right)$ : calcd for $\left(\mathrm{C}_{10} \mathrm{H}_{10} \mathrm{FO}\right)^{+}(\mathrm{M}+\mathrm{H})^{+} 165.0710$, found: 165.0706 .

(E)-4-( $m$-Tolyl)but-3-en-2-one (2j). Yellow liquid $\left(445 \mathrm{mg}, 84 \%\right.$ yield). $R_{\mathrm{f}}$ (25\% EtOAc/hexane): 0.61. IR ( $\mathrm{NaCl}): 3022,2921,2864,2735,1946$, 1881, 1819, 1790, 1691, 1667, 1613, 1585, 1359, 1257, 1229, 978, 779, $691,561 \mathrm{~cm}^{-1} .{ }^{1} \mathrm{H}$ NMR $\left(300.13 \mathrm{MHz}, \mathrm{CDCl}_{3}\right): \delta 2.03(\mathrm{~s}, 3 \mathrm{H}), 2.04(\mathrm{~s}, 3 \mathrm{H})$, $6.40\left(\mathrm{~d},{ }^{3} \mathrm{JHH}=16.3 \mathrm{~Hz}, 1 \mathrm{H}\right), 6.84-7.04(\mathrm{~m}, 4 \mathrm{H}), 7.17\left(\mathrm{~d},{ }^{3} \mathrm{JHH}=16.3 \mathrm{~Hz}\right.$, 1H) ppm. ${ }^{13} \mathrm{C}$ NMR $\left(75.5 \mathrm{MHz}, \mathrm{CDCl}_{3}\right): \delta 20.4\left(\mathrm{CH}_{3}\right), 26.5\left(\mathrm{CH}_{3}\right), 124.7$ $(\mathrm{CH}), 126.1(\mathrm{CH}), 128.0(\mathrm{CH}), 128.2(\mathrm{CH}), 130.5(\mathrm{CH}), 133.7(\mathrm{C}), 137.6$ (C), $142.5(\mathrm{CH}), 196.9$ (C) ppm. HRMS $\left(\mathrm{ESI}^{+}, \mathrm{m} / \mathrm{z}\right)$ : calcd for $\left(\mathrm{C}_{11} \mathrm{H}_{13} \mathrm{O}\right)^{+}$ $(\mathrm{M}+\mathrm{H})^{+}$161.0961, found: 161.0944

(E)-4-(Pyridin-2-yl)but-3-en-2-one (2k). Pale yellow liquid (340 mg, 70\% yield). $R_{\mathrm{f}}(17 \%$ hexane/EtOAc): 0.60. IR ( $\mathrm{NaCl}): 3052,3005,2921,1692$, $1669,1620,1582,1432,1359,1250,980,767 \mathrm{~cm}^{-1}$. ${ }^{1} \mathrm{H}$ NMR $(300.13 \mathrm{MHz}$, $\left.\mathrm{CDCl}_{3}\right): \delta 2.38(\mathrm{~s}, 3 \mathrm{H}), 7.11\left(\mathrm{~d},{ }^{3} \mathrm{JHH}_{\mathrm{HH}}=16.0 \mathrm{~Hz}, 1 \mathrm{H}\right), 7.26\left(\mathrm{ddd},{ }^{3} \mathrm{JHH}_{\mathrm{H}}=7.9\right.$, $\left.{ }^{3} J_{\mathrm{HH}}=4.8,{ }^{4} \mathrm{JHH}_{\mathrm{HH}}=1.1 \mathrm{~Hz} .1 \mathrm{H}\right), 7.43-7.54(\mathrm{~m}, 2 \mathrm{H}), 7.70$ (apparent td, ${ }^{3} \mathrm{JHH}_{\mathrm{HH}}=$ $\left.7.7,{ }^{4} \mathrm{JHH}_{\mathrm{HH}}=1.8 \mathrm{~Hz}, 1 \mathrm{H}\right), 8.63\left(\mathrm{ddd},{ }^{3} \mathrm{JHH}_{\mathrm{HH}}=4.8,{ }^{4} \mathrm{JHH}_{\mathrm{HH}}=1.9,{ }^{5} \mathrm{JHH}=0.9 \mathrm{~Hz}\right.$, 1H) ppm. ${ }^{13} \mathrm{C} \mathrm{NMR}\left(75.5 \mathrm{MHz}, \mathrm{CDCl}_{3}\right): \delta 28.2\left(\mathrm{CH}_{3}\right), 124.3(\mathrm{CH}), 124.4$ $(\mathrm{CH}), 130.3(\mathrm{CH}), 136.9(\mathrm{CH}), 142.0(\mathrm{CH}), 150.3(\mathrm{CH}), 153.2(\mathrm{C}), 198.6$ (C) ppm. HRMS $\left(\mathrm{ESI}^{+}, \mathrm{m} / \mathrm{z}\right)$ : calcd for $\left(\mathrm{C}_{9} \mathrm{H}_{10} \mathrm{NO}\right)^{+}(\mathrm{M}+\mathrm{H})^{+}$148.0757, found: 148.0751 .

(E)-4-(Pyridin-3-yl)but-3-en-2-one (2I). Pale yellow solid (383 mg, 79\% yield). $R_{\mathrm{f}}(17 \%$ hexane/EtOAc): 0.37 . Mp: 33-35 ㅇ. IR ( $\mathrm{NaCl}): 3031,3006$, 2921, 1693, 1672, 1613, 1415, 1360, 1258, 980, 797, $705 \mathrm{~cm}^{-1} .{ }^{1} \mathrm{H}$ NMR $\left(300.13 \mathrm{MHz}, \mathrm{CDCl}_{3}\right): \delta 2.37(\mathrm{~s}, 3 \mathrm{H}), 6.74\left(\mathrm{~d},{ }^{3} \mathrm{JHH}_{\mathrm{HH}}=16.4 \mathrm{~Hz}, 1 \mathrm{H}\right), 7.31(\mathrm{dd}$, $\left.{ }^{3} J_{\mathrm{HH}}=8.0,{ }^{3} \mathrm{JHH}_{\mathrm{HH}}=4.8 \mathrm{~Hz}, 1 \mathrm{H}\right), 7.47\left(\mathrm{~d},{ }^{3} \mathrm{HHH}=16.4 \mathrm{~Hz}, 1 \mathrm{H}\right), 7.83$ (apparent dt, $\left.{ }^{3} \mathrm{JHH}_{\mathrm{HH}}=8.0,{ }^{4} \mathrm{JHH}_{\mathrm{HH}}=2.0 \mathrm{~Hz}, 1 \mathrm{H}\right), 8.58\left(\mathrm{dd},{ }^{3} \mathrm{HHH}_{\mathrm{HH}}=4.8,{ }^{4} \mathrm{~J}_{\mathrm{HH}}=1.6 \mathrm{~Hz}, 1 \mathrm{H}\right)$, $8.72\left(\mathrm{~d},{ }^{4} \mathrm{JHH}=2.3 \mathrm{~Hz}, 1 \mathrm{H}\right) \mathrm{ppm} .{ }^{13} \mathrm{C} \mathrm{NMR}\left(75.5 \mathrm{MHz}, \mathrm{CDCl}_{3}\right): \delta 27.8\left(\mathrm{CH}_{3}\right)$, $123.9(\mathrm{CH}), 128.8(\mathrm{CH}), 130.3(\mathrm{C}), 134.3(\mathrm{CH}), 139.5(\mathrm{CH}), 150.0(\mathrm{CH})$, $151.3(\mathrm{CH}), 197.8(\mathrm{C})$ ppm. HRMS $\left(\mathrm{ESI}^{+}, \mathrm{m} / \mathrm{z}\right)$ : calcd for $\left(\mathrm{C}_{9} \mathrm{H}_{10} \mathrm{NO}\right)^{+}$ $(\mathrm{M}+\mathrm{H})^{+}$148.0757, found: 148.0751 .

(E)-4-(Furan-2-yl)but-3-en-2-one (2m). Orange solid (323 mg, 72\% yield). $R_{\mathrm{f}}(25 \%$ EtOAc/hexane): 0.50. Mp: 35-37 으. IR ( NaCl): 3144, 3126, 2921, $1687,1665,1611,1359,1253,1018,969,750 \mathrm{~cm}^{-1}$. ${ }^{1} \mathrm{H}$ NMR $(300.13 \mathrm{MHz}$, $\left.\mathrm{CDCl}_{3}\right): \delta 2.31(\mathrm{~s}, 3 \mathrm{H}), 6.47\left(\mathrm{dd},{ }^{3} \mathrm{JHH}_{\mathrm{H}}=3.4,{ }^{3} \mathrm{JHH}_{\mathrm{HH}}=1.8 \mathrm{~Hz}, 1 \mathrm{H}\right), 6.60(\mathrm{~d}$, $\left.{ }^{3} J_{H H}=16.0 \mathrm{~Hz}, 1 \mathrm{H}\right), 6.65\left(\mathrm{~d},{ }^{3} \mathrm{JHH}_{\mathrm{HH}}=3.4 \mathrm{~Hz}, 1 \mathrm{H}\right), 7.26\left(\mathrm{~d},{ }^{3} \mathrm{JHH}_{\mathrm{HH}}=15.9 \mathrm{~Hz}\right.$, $1 \mathrm{H}), 7.49\left(\mathrm{~d},{ }^{3} \mathrm{JHH}_{\mathrm{HH}}=1.4 \mathrm{~Hz}, 1 \mathrm{H}\right) \mathrm{ppm} .{ }^{13} \mathrm{C} \mathrm{NMR}\left(75.5 \mathrm{MHz}, \mathrm{CDCl}_{3}\right): \delta 28.0$ $\left(\mathrm{CH}_{3}\right), 112.7(\mathrm{CH}), 115.8(\mathrm{CH}), 124.4(\mathrm{CH}), 129.5(\mathrm{CH}), 145.1(\mathrm{CH}), 151.0$ (C), 197.9 (C) ppm. HRMS $\left(\mathrm{ESI}^{+}, \mathrm{m} / \mathrm{z}\right)$ : calcd for $\left(\mathrm{C}_{8} \mathrm{H}_{9} \mathrm{O}_{2}\right)^{+}(\mathrm{M}+\mathrm{H})^{+}$ 137.0597, found: 137.0596 .

(E)-4-(Furan-3-yl)but-3-en-2-one (2n). Brown solid (409 mg, 91\% yield). $R_{\mathrm{f}}(25 \%$ EtOAc/hexane): 0.45 . Mp: $44-45 \stackrel{\circ}{\circ} \mathrm{C} . \mathrm{IR}(\mathrm{NaCl}): 3132,3117,2926$, $1661,1627,1361,1274,1258,1160,1017,971,870,798 \mathrm{~cm}^{-1} .{ }^{1} \mathrm{H}$ NMR 
(300.13 MHz, CDCl 3 ): $\delta 2.31(\mathrm{~s}, 3 \mathrm{H}), 6.43\left(\mathrm{~d},{ }^{3}{ }^{\mathrm{HH}}=15.7 \mathrm{~Hz}, 1 \mathrm{H}\right), 6.57-$ $6.60(\mathrm{~m}, 1 \mathrm{H}), 7.37-7.45(\mathrm{~m}, 2 \mathrm{H}), 7.67\left(\mathrm{~d},{ }^{3} \mathrm{HHH}=0.9 \mathrm{~Hz}, 1 \mathrm{H}\right) \mathrm{ppm} .{ }^{13} \mathrm{C} \mathrm{NMR}$ (75.5 MHz, $\left.\mathrm{CDCl}_{3}\right): \delta 27.4\left(\mathrm{CH}_{3}\right), 107.5(\mathrm{CH}), 122.9(\mathrm{C}), 127.3(\mathrm{CH}), 133.5$ $(\mathrm{CH}), 144.7(\mathrm{CH}), 145.0(\mathrm{CH}), 198.2(\mathrm{C}) \mathrm{ppm}$. HRMS (ESI $\left.{ }^{+}, \mathrm{m} / \mathrm{z}\right)$ : calcd for $\left(\mathrm{C}_{8} \mathrm{H}_{9} \mathrm{O}_{2}\right)^{+}(\mathrm{M}+\mathrm{H})^{+} 137.0597$, found: 137.0593 .

(E)-4-(Thiophen-2-yl)but-3-en-2-one (20). Orange wax (312 mg, 62\% yield). $R_{\mathrm{f}}(25 \% \mathrm{EtOAc/hexane):} \mathrm{0.50.} \mathrm{IR} \mathrm{(NaCl):} \mathrm{3104,} \mathrm{3085,} \mathrm{2920,} 1664$, 1595, 1423, 1254, 1200, 1046, 965, $707 \mathrm{~cm}^{-1} .{ }^{1} \mathrm{H}$ NMR $(300.13 \mathrm{MHz}$, $\left.\mathrm{CDCl}_{3}\right): \delta 2.03(\mathrm{~s}, 3 \mathrm{H}), 6.23\left(\mathrm{~d},{ }^{3} \mathrm{JHH}=15.9 \mathrm{~Hz}, 1 \mathrm{H}\right), 6.77\left(\mathrm{dd},{ }^{3} \mathrm{JHH}_{\mathrm{HH}}=5.1\right.$, $\left.{ }^{3} J_{H H}=3.6 \mathrm{~Hz}, 1 \mathrm{H}\right), 7.01\left(\mathrm{~d},{ }^{3} \mathrm{JHH}_{\mathrm{HH}}=3.6 \mathrm{~Hz}, 1 \mathrm{H}\right), 7.13\left(\mathrm{~d},{ }^{3} \mathrm{JHH}_{\mathrm{HH}}=5.1 \mathrm{~Hz}, 1 \mathrm{H}\right)$, $7.36\left(\mathrm{~d},{ }^{3} \mathrm{JHH}_{\mathrm{HH}}=15.9 \mathrm{~Hz}, 1 \mathrm{H}\right) \mathrm{ppm} .{ }^{13} \mathrm{C} \mathrm{NMR}\left(75.5 \mathrm{MHz}, \mathrm{CDCl}_{3}\right): \delta 26.8$ $\left(\mathrm{CH}_{3}\right), 125.1(\mathrm{CH}), 127.7(\mathrm{CH}), 128.4(\mathrm{CH}), 131.0(\mathrm{CH}), 135.0(\mathrm{CH}), 139.1$ (C), 196.7 (C) ppm. HRMS $\left(\mathrm{ESI}^{+}, \mathrm{m} / \mathrm{z}\right)$ : calcd for $\left(\mathrm{C}_{8} \mathrm{H}_{8} \mathrm{NaOS}\right)^{+}(\mathrm{M}+\mathrm{Na})^{+}$ 175.0188, found: 175.0190 .

(E)-4-(Thiophen-3-yl)but-3-en-2-one (2p). Pale yellow solid (474 mg, $94 \%$ yield). $R_{f}(25 \%$ EtOAc/hexane): 0.45 . Mp: 67-68 ㅇ․ IR (NaCl): 3107 , $3008,2922,1665,1636,1615,1358,1265,1159,975,876,784 \mathrm{~cm}^{-1} .{ }^{1} \mathrm{H}$ $\operatorname{NMR}\left(300.13 \mathrm{MHz}, \mathrm{CDCl}_{3}\right): \delta 2.34(\mathrm{~s}, 3 \mathrm{H}), 6.54\left(\mathrm{~d},{ }^{3} \mathrm{JHH}_{\mathrm{HH}}=16.3 \mathrm{~Hz}, 1 \mathrm{H}\right)$, $7.30\left(\mathrm{dd},{ }^{3} \mathrm{JHH}_{\mathrm{HH}}=5.1,{ }^{4} \mathrm{~J}_{\mathrm{HH}}=1.1 \mathrm{~Hz}, 1 \mathrm{H}\right), 7.35\left(\mathrm{dd},{ }^{3} \mathrm{~J}_{\mathrm{HH}}=5.1,{ }^{4} \mathrm{JHH}_{\mathrm{HH}}=3.4 \mathrm{~Hz}\right.$, $1 \mathrm{H}), 7.46-7.55(\mathrm{~m}, 2 \mathrm{H})$ ppm. ${ }^{13} \mathrm{C}$ NMR $\left(75.5 \mathrm{MHz}, \mathrm{CDCl}_{3}\right): \delta 27.5\left(\mathrm{CH}_{3}\right)$, $125.3(\mathrm{CH}), 127.1(\mathrm{CH}), 127.2(\mathrm{CH}), 128.7(\mathrm{CH}), 137.0(\mathrm{CH}), 137.8(\mathrm{C})$, 198.7 (C) ppm. HRMS $\left(\mathrm{ESI}^{+}, \mathrm{m} / \mathrm{z}\right)$ : calcd for $\left(\mathrm{C}_{8} \mathrm{H}_{8} \mathrm{NaOS}\right)^{+}(\mathrm{M}+\mathrm{Na})^{+}$ 175.0188, found: 175.0181 .

\section{Typical procedure for the synthesis of alcohols 1a-p}

Alcohols 1a-j were synthesised following the procedure described by Gładkowski et al. for alcohol 1a as follows:[56] A solution of $\mathrm{NaBH}_{4}(170.2$ $\mathrm{mg}, 4.5 \mathrm{mmol}$ ) in water (1 mL) was added dropwise to a stirring solution of the corresponding (3E)-4-(het)arylbut-3-en-2-one 2a-p (3 mmol) in $\mathrm{MeOH}$ $(10 \mathrm{~mL})$ at $0 \stackrel{\circ}{\circ}$. The reaction mixture was first stirred for $1 \mathrm{~h}$ in an ice bath and then $2 \mathrm{~h}$ at room temperature. Afterwards, hot water was added and the product was extracted with $\mathrm{CH}_{2} \mathrm{Cl}_{2}(3 \times 15 \mathrm{~mL})$ and the combined organic phases were washed with brine $(5 \mathrm{~mL})$. The organic layer was dried over anhydrous $\mathrm{Na}_{2} \mathrm{SO}_{4}$, filtered and the solvent evaporated under reduced pressure. The reaction crudes of allylic alcohols were purified by column chromatography on silica gel, yielding the corresponding alcohols 1a-j (46-99\% yield, eluent 50\% Et $2 \mathrm{O} / \mathrm{hexane}), \mathbf{1 k}$ and $\mathbf{1 I}$ (87-91\% yield, eluent $83 \%$ EtOAc/hexane) and 1m-p $(71-91 \%$ yield, eluent $25 \%$ EtOAc/hexane).

(E)-4-Phenylbut-3-en-2-ol (1a). White solid (445 mg, $99 \%$ yield). $R_{\mathrm{f}}(50 \%$ $\mathrm{Et}_{2} \mathrm{O} /$ hexane): 0.44 . Mp: $35-36 \stackrel{\circ}{\circ} \mathrm{C}$. IR ( $\left.\mathrm{NaCl}\right): 3376,3026,2973,2926$, 2872, 1949, 1879, 1807, 1751, 1494, 1449, 1141, 1060, 967, 748, $693 \mathrm{~cm}$ 1. ${ }^{1} \mathrm{H}$ NMR $\left(300.13 \mathrm{MHz}, \mathrm{CDCl}_{3}\right): \delta 1.38\left(\mathrm{~d},{ }^{3} \mathrm{JHH}=6.4 \mathrm{~Hz}, 3 \mathrm{H}\right), 1.81(\mathrm{br} \mathrm{s}$, $1 \mathrm{H}), 4.45-4.54(\mathrm{~m}, 1 \mathrm{H}), 6.27\left(\mathrm{dd},{ }^{3} \mathrm{~J}_{\mathrm{HH}}=15.9,{ }^{3} \mathrm{JHH}_{\mathrm{HH}}=6.4 \mathrm{~Hz}, 1 \mathrm{H}\right), 6.57(\mathrm{~d}$, $\left.{ }^{3} \mathrm{JHH}_{\mathrm{HH}} 15.9 \mathrm{~Hz}, 1 \mathrm{H}\right), 7.22-7.27(\mathrm{~m}, 1 \mathrm{H}), 7.30-7.40(\mathrm{~m}, 4 \mathrm{H}) \mathrm{ppm} .{ }^{13} \mathrm{C} \mathrm{NMR}$ $\left(75.5 \mathrm{MHz}, \mathrm{CDCl}_{3}\right): \delta 23.5\left(\mathrm{CH}_{3}\right), 69.0\left(\mathrm{CH}_{3}\right), 126.6(2 \mathrm{CH}), 127.8(\mathrm{CH})$, $128.7(2 \mathrm{CH}), 129.5(\mathrm{CH}), 133.7(\mathrm{CH}), 136.8(\mathrm{C}) \mathrm{ppm}$. HRMS (ESl+, $\mathrm{m} / \mathrm{z})$ : calcd for $\left(\mathrm{C}_{10} \mathrm{H}_{12} \mathrm{NaO}\right)^{+}(\mathrm{M}+\mathrm{Na})^{+} 171.0780$, found: 171.0785 .

(E)-4-(4-Methoxyphenyl)but-3-en-2-ol (1b). White solid $(469 \mathrm{mg}, 88 \%$ yield). $R_{\mathrm{f}}\left(50 \% \mathrm{Et}_{2} \mathrm{O} / \mathrm{hexane}\right): 0.31 . \mathrm{Mp}: 75-78 \stackrel{\circ}{\circ} \mathrm{C}$. IR $(\mathrm{NaCl}): 3424,2956$, 2838, 1891, 1513, 1255, 1032, $808 \mathrm{~cm}^{-1}$. ${ }^{1} \mathrm{H}$ NMR $\left(300.13 \mathrm{MHz}, \mathrm{CDCl}_{3}\right): \delta$ $1.36\left(\mathrm{~d},{ }^{3} \mathrm{JHH}_{\mathrm{HH}}=6.4 \mathrm{~Hz}, 3 \mathrm{H}\right), 1.69(\mathrm{~s}, 1 \mathrm{H}), 3.81(\mathrm{~s}, 3 \mathrm{H}), 4.42-4.51(\mathrm{~m}, 1 \mathrm{H})$, $6.12\left(\mathrm{dd},{ }^{3} \mathrm{JHH}=15.9,{ }^{3} \mathrm{JHH}_{\mathrm{HH}}=6.6 \mathrm{~Hz}, 1 \mathrm{H}\right), 6.50\left(\mathrm{~d},{ }^{3} \mathrm{HH}=15.9 \mathrm{~Hz}, 1 \mathrm{H}\right), 6.82$ $6.89(\mathrm{~m}, 2 \mathrm{H}), 7.28-7.36(\mathrm{~m}, 2 \mathrm{H}) \mathrm{ppm} .{ }^{13} \mathrm{C} \mathrm{NMR}\left(75.5 \mathrm{MHz}, \mathrm{CDCl}_{3}\right): \delta 23.6$ $\left(\mathrm{CH}_{3}\right), 55.4\left(\mathrm{CH}_{3}\right), 69.2(\mathrm{CH}), 114.1(2 \mathrm{CH}), 127.8(2 \mathrm{CH}), 129.1(\mathrm{CH}), 129.5$ (C), $131.5(\mathrm{CH}), 159.4$ (C) ppm. HRMS (ESl $\left.{ }^{+}, \mathrm{m} / \mathrm{z}\right)$ : calcd for $\left(\mathrm{C}_{11} \mathrm{H}_{14} \mathrm{NaO}_{2}\right)^{+}(\mathrm{M}+\mathrm{Na})^{+}$201.0886, found: 201.0875 .

(E)-4-(4-Chlorophenyl)but-3-en-2-ol (1c). White solid (351 mg, 64\% yield). $R_{f}\left(50 \% \mathrm{Et}_{2} \mathrm{O} /\right.$ hexane): 0.48. Mp: $63-65^{\circ} \mathrm{C}$. IR ( $\left.\mathrm{NaCl}\right): 3375,3052$, 2975, 1492, 1265, 1092, $739 \mathrm{~cm}^{-1}$. ${ }^{1} \mathrm{H}$ NMR $\left(300.13 \mathrm{MHz}, \mathrm{CDCl}_{3}\right): \delta 1.37$ $\left(\mathrm{d},{ }^{3} \mathrm{JHH}_{\mathrm{HH}}=6.4 \mathrm{~Hz}, 3 \mathrm{H}\right), 1.77(\mathrm{br} \mathrm{s}, 1 \mathrm{H}), 4.44-4.52(\mathrm{~m}, 1 \mathrm{H}), 6.23\left(\mathrm{dd},{ }^{3} \mathrm{HHH}=\right.$ $\left.15.9,{ }^{3} \mathrm{JHH}_{\mathrm{HH}}=6.4 \mathrm{~Hz}, 1 \mathrm{H}\right), 6.52\left(\mathrm{dd},{ }^{3} \mathrm{JHH}_{\mathrm{HH}}=15.9,{ }^{4} \mathrm{JHH}_{\mathrm{HH}}=1.1 \mathrm{~Hz}, 1 \mathrm{H}\right), 7.28(\mathrm{br}$ s, 4H) ppm. ${ }^{13} \mathrm{C} \mathrm{NMR}\left(75.5 \mathrm{MHz}, \mathrm{CDCl}_{3}\right): \delta 23.5\left(\mathrm{CH}_{3}\right), 68.9(\mathrm{CH}), 127.8$ $(2 \mathrm{CH}), 128.2(\mathrm{CH}), 128.9(2 \mathrm{CH}), 133.3(\mathrm{C}), 134.3(\mathrm{CH}), 135.3(\mathrm{C}) \mathrm{ppm}$. HRMS $\left(E S l^{+}, \mathrm{m} / \mathrm{z}\right)$ : calcd for $\left(\mathrm{C}_{10} \mathrm{H}_{11} \mathrm{CINaO}\right)^{+}(\mathrm{M}+\mathrm{Na})^{+} 205.0391$, found: 205.0394

(E)-4-(4-Fluorophenyl)but-3-en-2-ol (1d). White solid (230 mg, 46\% yield). $R_{\mathrm{f}}\left(50 \% \mathrm{Et}_{2} \mathrm{O} / \mathrm{hexane}\right): 0.46 . \mathrm{Mp}: 38-40 \stackrel{\circ}{\circ} \mathrm{C}$. IR (NaCl): 3430,3071 $2977,1891,1601,1508,1372,1227,968,857 \mathrm{~cm}^{-1}$. ${ }^{1} \mathrm{H}$ NMR $(300.13 \mathrm{MHz}$, $\left.\mathrm{CDCl}_{3}\right): \delta 1.36\left(\mathrm{~d},{ }^{3} \mathrm{HHH}_{\mathrm{HH}}=6.4 \mathrm{~Hz}, 3 \mathrm{H}\right), 1.87(\mathrm{br} \mathrm{s}, 1 \mathrm{H}), 4.43-4.51(\mathrm{~m}, 1 \mathrm{H})$, $6.17\left(\mathrm{dd},{ }^{3} \mathrm{JHH}_{\mathrm{HH}}=15.9,{ }^{3} \mathrm{~J}_{\mathrm{HH}}=6.3 \mathrm{~Hz}, 1 \mathrm{H}\right), 6.52\left(\mathrm{~d},{ }^{3} \mathrm{JHH}_{\mathrm{HH}}=15.9 \mathrm{~Hz}, 1 \mathrm{H}\right), 6.96-$ $7.03(\mathrm{~m}, 2 \mathrm{H}), 7.29-7.36(\mathrm{~m}, 2 \mathrm{H}) \mathrm{ppm} .{ }^{13} \mathrm{C}$ NMR $\left(75.5 \mathrm{MHz}, \mathrm{CDCl}_{3}\right): \delta 23.6$ $\left(\mathrm{CH}_{3}\right), 68.9(\mathrm{CH}), 115.6(\mathrm{~d}, J=21.6 \mathrm{~Hz}, 2 \mathrm{CH}), 128.1(\mathrm{~d}, J=8.3 \mathrm{~Hz}, 2 \mathrm{CH})$, $128.3(\mathrm{CH}), 133.0$ (d, $J=3.3 \mathrm{~Hz}, \mathrm{C}), 133.4$ (d, $J=1.9 \mathrm{~Hz}, \mathrm{CH}), 162.4$ (d, $J$ $=246.5 \mathrm{~Hz}, \mathrm{C}) \mathrm{ppm} .{ }^{19} \mathrm{~F} \mathrm{NMR}\left(282 \mathrm{MHz}, \mathrm{CDCl}_{3}\right): \delta-114.5 \mathrm{ppm}$. HRMS $\left(\mathrm{ESI}^{+}, \mathrm{m} / \mathrm{z}\right)$ : calcd for $\left(\mathrm{C}_{10} \mathrm{H}_{11} \mathrm{FNaO}\right)^{+}(\mathrm{M}+\mathrm{Na})^{+} 189.0686$, found: 189.0687 . 4-(4-Bromophenyl)but-3-en-2-ol (1e). White solid (387 mg, 57\% yield). $R_{\mathrm{f}}\left(50 \% \mathrm{Et}_{2} \mathrm{O} / \mathrm{hexane}\right): 0.38$. Mp: $46-48{ }^{\circ} \mathrm{C}$. IR $(\mathrm{NaCl}): 3385,2972,1898$, $1655,1487,1072,1009,805 \mathrm{~cm}^{-1} .{ }^{1} \mathrm{H}$ NMR $\left(300.13 \mathrm{MHz}, \mathrm{CDCl}_{3}\right): \delta 1.36$ $\left(\mathrm{d},{ }^{3} \mathrm{JHH}_{\mathrm{HH}}=6.4 \mathrm{~Hz}, 3 \mathrm{H}\right), 1.77(\mathrm{br} \mathrm{s}, 1 \mathrm{H}), 4.43-4.52(\mathrm{~m}, 1 \mathrm{H}), 6.24\left(\mathrm{dd},{ }^{3} \mathrm{JHH}_{\mathrm{HH}}=\right.$ $\left.15.9,{ }^{3} \mathrm{JHH}_{\mathrm{HH}}=6.4 \mathrm{~Hz}, 1 \mathrm{H}\right), 6.50\left(\mathrm{~d},{ }^{3} \mathrm{~J}_{\mathrm{HH}}=15.9 \mathrm{~Hz}, 1 \mathrm{H}\right), 7.21-7.24(\mathrm{~m}, 2 \mathrm{H})$, 7.40-7.45 (m, 2H) ppm. ${ }^{13} \mathrm{C} \mathrm{NMR}\left(75.5 \mathrm{MHz}, \mathrm{CDCl}_{3}\right): \delta 23.5\left(\mathrm{CH}_{3}\right), 68.9$ $(\mathrm{CH}), 121.5(\mathrm{C}), 128.1(2 \mathrm{CH}), 128.3(\mathrm{CH}), 131.8(2 \mathrm{CH}), 134.4(\mathrm{CH}), 135.8$ (C) ppm. HRMS $\left(\mathrm{ESI}^{+}, \mathrm{m} / \mathrm{z}\right)$ : calcd for $\left(\mathrm{C}_{10} \mathrm{H}_{10} \mathrm{Br}\right)^{+}(\mathrm{M}-\mathrm{OH})^{+} 208.9960$, found: 208.9971.

(E)-4-(3-Methoxyphenyl)but-3-en-2-ol (1f). Pale yellow liquid $(417 \mathrm{mg}$ $78 \%$ yield). $R_{\mathrm{f}}\left(50 \% \mathrm{Et}_{2} \mathrm{O} /\right.$ hexane): $0.37 . \mathrm{IR}(\mathrm{NaCl}): 3425,2971,2836$ 1926, 1719, 1599, 1288, 1047, 969, 779, $691 \mathrm{~cm}^{-1}$. ${ }^{1} \mathrm{H}$ NMR $(300.13 \mathrm{MHz}$ $\left.\mathrm{CDCl}_{3}\right): \delta 1.36\left(\mathrm{~d},{ }^{3} \mathrm{HHH}_{\mathrm{HH}}=6.4 \mathrm{~Hz}, 3 \mathrm{H}\right), 2.87(\mathrm{br} \mathrm{s}, 1 \mathrm{H}), 3.78(\mathrm{~s}, 3 \mathrm{H}), 4.41-$ $4.50(\mathrm{~m}, 1 \mathrm{H}), 6.25\left(\mathrm{dd},{ }^{3} \mathrm{HH}=15.9,{ }^{3} \mathrm{~J}_{\mathrm{HH}}=6.4 \mathrm{~Hz}, 1 \mathrm{H}\right), 6.51\left(\mathrm{~d},{ }^{3} \mathrm{JHH}_{\mathrm{HH}}=15.9\right.$ $\mathrm{Hz}, 1 \mathrm{H}), 6.79\left(\mathrm{dd},{ }^{3} \mathrm{JHH}_{\mathrm{HH}}=6.4,{ }^{4} \mathrm{~J}_{\mathrm{HH}}=2.6 \mathrm{~Hz}, 1 \mathrm{H}\right), 6.91$ (apparent t, ${ }^{3} \mathrm{JHH}_{\mathrm{HH}}=$ $2.6,1 \mathrm{H}), 6.96\left(\mathrm{~d},{ }^{3} \mathrm{JHH}_{\mathrm{HH}}=7.9 \mathrm{~Hz}, 1 \mathrm{H}\right), 7.22\left(\right.$ apparent t $\left.{ }^{3} \mathrm{JHH}=7.9 \mathrm{~Hz}, 1 \mathrm{H}\right)$ ppm. ${ }^{13} \mathrm{C}$ NMR $\left(75.5 \mathrm{MHz}, \mathrm{CDCl}_{3}\right): \delta 23.3\left(\mathrm{CH}_{3}\right), 55.1\left(\mathrm{CH}_{3}\right), 68.6(\mathrm{CH})$, $111.7(\mathrm{CH}), 113.2(\mathrm{CH}), 119.1(\mathrm{CH}), 129.0(\mathrm{CH}), 129.5(\mathrm{CH}), 134.0(\mathrm{CH})$ 138.2 (C), 159.7 (C) ppm. HRMS $\left(\mathrm{ESI}^{+}, \mathrm{m} / \mathrm{z}\right)$ : calcd for $\left(\mathrm{C}_{11} \mathrm{H}_{14} \mathrm{NaO}_{2}\right)^{+}$ $(\mathrm{M}+\mathrm{Na})^{+} 201.0886$, found: 201.0890 .

(E)-4-(2-Methoxyphenyl)but-3-en-2-ol (1 g). Pale yellow liquid (435 mg, $81 \%$ yield). $R_{f}\left(50 \% \mathrm{Et}_{2} \mathrm{O} /\right.$ hexane $): 0.39$. IR ( $\left.\mathrm{NaCl}\right): 3396,2970,2837$ 1899, 1688, 1598, 1239, 974, $753 \mathrm{~cm}^{-1} .{ }^{1} \mathrm{H}$ NMR $\left(300.13 \mathrm{MHz}, \mathrm{CDCl}_{3}\right): \delta$ $1.41\left(\mathrm{~d},{ }^{3} \mathrm{JHH}=6.4 \mathrm{~Hz}, 3 \mathrm{H}\right), 3.01(\mathrm{br} \mathrm{s}, 1 \mathrm{H}), 3.83(\mathrm{~s}, 3 \mathrm{H}), 4.47-4.56(\mathrm{~m}, 1 \mathrm{H})$, $6.31\left(\mathrm{dd},{ }^{3} \mathrm{HHH}_{\mathrm{HH}}=16.0,{ }^{3} \mathrm{JHH}_{\mathrm{HH}}=6.4 \mathrm{~Hz}, 1 \mathrm{H}\right), 6.85-6.99(\mathrm{~m}, 3 \mathrm{H}), 7.25\left(\mathrm{ddd},{ }^{3} \mathrm{JHH}_{\mathrm{HH}}\right.$ $\left.=8.2,{ }^{3} J_{\mathrm{HH}}=7.5,{ }^{4} \mathrm{JHH}_{\mathrm{HH}}=1.7 \mathrm{~Hz}, 1 \mathrm{H}\right), 7.46\left(\mathrm{dd},{ }^{3}{ }_{\mathrm{HH}}=7.5,{ }^{4} \mathrm{JHH}_{\mathrm{HH}}=1.7 \mathrm{~Hz}\right.$, 1H) ppm. ${ }^{13} \mathrm{C}$ NMR $\left(75.5 \mathrm{MHz}, \mathrm{CDCl}_{3}\right): \delta 23.3\left(\mathrm{CH}_{3}\right), 55.2\left(\mathrm{CH}_{3}\right), 69.0(\mathrm{CH})$, $110.7(\mathrm{CH}), 120.5(\mathrm{CH}), 123.9(\mathrm{CH}), 125.7(\mathrm{C}), 126.7(\mathrm{CH}), 128.5(\mathrm{CH})$, $134.3(\mathrm{CH}), 156.5(\mathrm{C}) \mathrm{ppm}$. HRMS $\left(\mathrm{ESI}^{+}, \mathrm{m} / \mathrm{z}\right)$ : calcd for $\left(\mathrm{C}_{11} \mathrm{H}_{14} \mathrm{NaO}_{2}\right)^{+}$ $(\mathrm{M}+\mathrm{Na})^{+} 201.0886$, found: 201.0888 .

(E)-4-(3-Fluorophenyl)but-3-en-2-ol (1h). Pale yellow liquid $(354 \mathrm{mg}$, $71 \%$ yield). $R_{f}\left(50 \% \mathrm{Et}_{2} \mathrm{O} /\right.$ hexane): 0.52 . IR ( $\left.\mathrm{NaCl}\right): 3371,3075,3037$, 2974, 2928, 1935, 1857, 1585, 1488, 1447, 1265, 1144, 961, $781 \mathrm{~cm}^{-1} .{ }^{1} \mathrm{H}$ $\operatorname{NMR}\left(300.13 \mathrm{MHz}, \mathrm{CDCl}_{3}\right): \delta 1.41\left(\mathrm{~d},{ }^{3} \mathrm{JHH}=6.4 \mathrm{~Hz}, 3 \mathrm{H}\right), 2.49(\mathrm{br} \mathrm{s}, 1 \mathrm{H})$, 4.48-4.56 (m, 1H), $6.30\left(\mathrm{dd},{ }^{3} \mathrm{JHH}_{\mathrm{HH}}=15.9,{ }^{3} \mathrm{JHH}=6.1 \mathrm{~Hz}, 1 \mathrm{H}\right), 6.56\left(\mathrm{~d},{ }^{3} \mathrm{~J}_{\mathrm{HH}}\right.$ $=15.9 \mathrm{~Hz}, 1 \mathrm{H}), 6.93-7.00(\mathrm{~m}, 1 \mathrm{H}), 7.10(\mathrm{ddd}, J=10.2, J=2.6, J=1.6 \mathrm{~Hz}$, $1 \mathrm{H}), 7.16(\mathrm{~d}, J=7.7 \mathrm{~Hz}, 1 \mathrm{H}), 7.27-7.34(\mathrm{~m}, 1 \mathrm{H}) \mathrm{ppm} .{ }^{13} \mathrm{C} \mathrm{NMR}(75.5 \mathrm{MHz}$, $\left.\mathrm{CDCl}_{3}\right): \delta 23.5\left(\mathrm{CH}_{3}\right), 68.8(\mathrm{CH}), 113.0(\mathrm{~d}, J=21.8 \mathrm{~Hz}, \mathrm{CH}), 114.6(\mathrm{~d}, J=$ $21.4 \mathrm{~Hz}, \mathrm{CH}), 122.5(\mathrm{~d}, J=2.8 \mathrm{~Hz}, \mathrm{CH}), 128.3(\mathrm{~d}, J=2.5 \mathrm{~Hz}, \mathrm{CH}), 130.2$ (d, $J=8.4 \mathrm{~Hz}, \mathrm{CH}), 135.0(\mathrm{CH}), 139.2(\mathrm{~d}, J=7.8 \mathrm{~Hz}, \mathrm{C}), 163.2(\mathrm{~d}, J=$ $245.0 \mathrm{~Hz}, \mathrm{C}) \mathrm{ppm} .{ }^{19} \mathrm{~F} \mathrm{NMR}\left(282 \mathrm{MHz}, \mathrm{CDCl}_{3}\right): \delta-113.5 \mathrm{ppm}$. HRMS (ESI+, $\mathrm{m} / \mathrm{z})$ : calcd for $\left(\mathrm{C}_{10} \mathrm{H}_{11} \mathrm{FNaO}\right)^{+}(\mathrm{M}+\mathrm{Na})^{+} 189.0686$, found: 189.0695 . (E)-4-(2-Fluorophenyl)but-3-en-2-ol (1i). White wax (380 mg, $76 \%$ yield). $R_{\mathrm{f}}\left(50 \% \mathrm{Et}_{2} \mathrm{O} /\right.$ hexane): 0.56. IR ( $\left.\mathrm{NaCl}\right): 3431,2976,1488,1457,1229,970$, $756 \mathrm{~cm}^{-1} .{ }^{1} \mathrm{H}$ NMR $\left(300.13 \mathrm{MHz}, \mathrm{CDCl}_{3}\right): \delta 1.36\left(\mathrm{~d},{ }^{3} \mathrm{JHH}_{\mathrm{HH}}=6.4 \mathrm{~Hz}, 3 \mathrm{H}\right), 3.01$ (s, 1H), 4.44-452 (m, 1H), $6.34\left(\mathrm{dd},{ }^{3}{ }_{\mathrm{HH}}=16.1,{ }^{3}{ }_{\mathrm{HH}}=6.3 \mathrm{~Hz}, 1 \mathrm{H}\right), 6.71$ $\left(\mathrm{d},{ }^{3} \mathrm{JHH}_{\mathrm{HH}}=16.1 \mathrm{~Hz}, 1 \mathrm{H}\right), 6.97-7.08(\mathrm{~m}, 2 \mathrm{H}), 7.14-7.21(\mathrm{~m}, 1 \mathrm{H}), 7.41(\mathrm{td}, J=$ $7.7, J=1.8 \mathrm{~Hz}) \mathrm{ppm} .{ }^{13} \mathrm{C} \mathrm{NMR}\left(75.5 \mathrm{MHz}, \mathrm{CDCl}_{3}\right): \delta 23.3\left(\mathrm{CH}_{3}\right), 68.8(\mathrm{CH})$, $115.7(\mathrm{~d}, J=22.4 \mathrm{~Hz}, \mathrm{CH}), 121.5(\mathrm{~d}, J=3.7 \mathrm{~Hz}, \mathrm{CH}), 124.1(\mathrm{~d}, J=3.5 \mathrm{~Hz}$, $\mathrm{CH}), 124.5(\mathrm{~d}, J=12.2 \mathrm{~Hz}, \mathrm{C}), 127.5(\mathrm{~d}, J=3.7 \mathrm{~Hz}, \mathrm{CH}), 128.7(\mathrm{~d}, J=8.4$ 
$\mathrm{Hz}, \mathrm{CH}), 136.3$ (d, $J=4.5 \mathrm{~Hz}, \mathrm{CH}$ ), 160.3 (d, $J=248.8 \mathrm{~Hz}, \mathrm{C}) \mathrm{ppm} .{ }^{19} \mathrm{~F}$ NMR $\left(282 \mathrm{MHz}, \mathrm{CDCl}_{3}\right): \delta-118.1 \mathrm{ppm}$. HRMS $\left(\mathrm{ESI}^{+}, \mathrm{m} / \mathrm{z}\right)$ : calcd for $\left(\mathrm{C}_{10} \mathrm{H}_{11} \mathrm{FNaO}\right)^{+}(\mathrm{M}+\mathrm{Na})^{+}$189.0686, found: 189.0682 .

(E)-4-( $m$-Tolyl)but-3-en-2-ol (1j). Pale yellow liquid (414 mg, 85\% yield). $R_{\mathrm{f}}\left(50 \% \mathrm{Et}_{2} \mathrm{O} /\right.$ hexane): 0.46. IR ( $\left.\mathrm{NaCl}\right): 3405,2974,2923,2733,1943$, $1876,1606,1488,1261,970,779,694 \mathrm{~cm}^{-1} .{ }^{1} \mathrm{H}$ NMR $(300.13 \mathrm{MHz}$, $\left.\mathrm{CDCl}_{3}\right): \delta 1.40\left(\mathrm{~d},{ }^{3} \mathrm{JHH}_{\mathrm{HH}}=6.4 \mathrm{~Hz}, 3 \mathrm{H}\right), 2.38(\mathrm{~s}, 3 \mathrm{H}), 2.90(\mathrm{~s}, 1 \mathrm{H}), 4.45-4.54$ $(\mathrm{m}, 1 \mathrm{H}), 6.28\left(\mathrm{dd},{ }^{3} \mathrm{JHH}=15.9,{ }^{3} \mathrm{JHH}=6.4 \mathrm{~Hz}, 1 \mathrm{H}\right), 6.55\left(\mathrm{~d},{ }^{3} \mathrm{JHH}=15.9 \mathrm{~Hz}\right.$, $1 \mathrm{H})$, 7.07-7.13 (m, 1H), 7.18-7.28 (m, 3H). ${ }^{13} \mathrm{C}$ NMR $\left(75.5 \mathrm{MHz}, \mathrm{CDCl}_{3}\right): \delta$ $21.5\left(\mathrm{CH}_{3}\right), 23.5\left(\mathrm{CH}_{3}\right), 68.8(\mathrm{CH}), 123.7(\mathrm{CH}), 127.3(\mathrm{CH}), 128.4(\mathrm{CH})$, $128.5(\mathrm{CH}), 129.3(\mathrm{CH}), 133.5(\mathrm{CH}), 136.8(\mathrm{C}), 138.1(\mathrm{C})$ ppm. HRMS $\left(\mathrm{ESI}^{+}, \mathrm{m} / \mathrm{z}\right)$ : calcd for $\left(\mathrm{C}_{11} \mathrm{H}_{14} \mathrm{NaO}\right)^{+}(\mathrm{M}+\mathrm{Na})^{+} 185.0937$, found: 185.0945 . (E)-4-(Pyridin-2-yl)but-3-en-2-ol (1k). Pale yellow liquid (389 mg, 87\% yield). $R_{\mathrm{f}}(17 \%$ hexane/EtOAc): 0.40 . IR ( $\mathrm{NaCl}): 3375,2971,2926,2869$, $1656,1588,1565,1471,1432,1367,1300,1143,1062,999,854,766 \mathrm{~cm}$ 1. ${ }^{1} \mathrm{H}$ NMR $\left(300.13 \mathrm{MHz}, \mathrm{CDCl}_{3}\right): \delta 1.18\left(\mathrm{~d},{ }^{3} \mathrm{~J}_{\mathrm{HH}}=6.6 \mathrm{~Hz}, 3 \mathrm{H}\right), 4.29-4.41$ $(\mathrm{m}, 1 \mathrm{H}), 5.18(\mathrm{br} \mathrm{s}, 1 \mathrm{H}), 6.46-6.62(\mathrm{~m}, 2 \mathrm{H}), 6.81-6.90(\mathrm{~m}, 1 \mathrm{H}), 7.04(\mathrm{dd}$, ${ }^{3} J_{\mathrm{HH}}=7.9,{ }^{4} \mathrm{JHH}_{\mathrm{HH}}=1.2 \mathrm{~Hz}, 1 \mathrm{H}$ ), 7.35 (apparent td, ${ }^{3} \mathrm{JHH}_{\mathrm{HH}}=7.7,{ }^{4} \mathrm{JHH}_{\mathrm{HH}}=1.6 \mathrm{~Hz}$, $1 \mathrm{H}), 8.27\left(\mathrm{~d},{ }^{3} \mathrm{JHH}_{\mathrm{HH}} 4.9 \mathrm{~Hz}, 1 \mathrm{H}\right) \mathrm{ppm} .{ }^{13} \mathrm{C} \mathrm{NMR}\left(75.5 \mathrm{MHz}, \mathrm{CDCl}_{3}\right): \delta 23.0$ $\left(\mathrm{CH}_{3}\right), 67.2(\mathrm{CH}), 121.1(\mathrm{CH}), 121.7(\mathrm{CH}), 127.6(\mathrm{CH}), 136.4(\mathrm{CH}), 139.1$ $(\mathrm{CH}), 148.7(\mathrm{CH}), 155.2(\mathrm{C}) \mathrm{ppm}$. HRMS (ESI+ $\mathrm{m} / \mathrm{z})$ : calcd for $\left(\mathrm{C}_{9} \mathrm{H}_{12} \mathrm{NO}\right)^{+}$ $(\mathrm{M}+\mathrm{H})^{+} 150.0913$, found: 150.0913 .

(E)-4-(Pyridin-3-yl)but-3-en-2-ol (11). Pale yellow liquid (409 mg, 91\% yield). $R_{\mathrm{f}}(17 \%$ hexane/EtOAc): 0.25 . IR ( $\mathrm{NaCl}): 3373,2970,2926,2868$, $1654,1590,1572,1480,1417,1184,1143,1063,969,834,794,707 \mathrm{~cm}$ 1. ${ }^{1} \mathrm{H}$ NMR $\left(300.13 \mathrm{MHz}, \mathrm{CDCl}_{3}\right): \delta 1.18-1.34(\mathrm{~m}, 3 \mathrm{H}), 4.33-4.43(\mathrm{~m}, 1 \mathrm{H})$, $5.09(\mathrm{br} \mathrm{s}, 1 \mathrm{H}), 6.13-6.31(\mathrm{~m}, 1 \mathrm{H}), 6.40\left(\mathrm{dd},{ }^{3} \mathrm{JHH}_{\mathrm{HH}}=16.1,{ }^{4} \mathrm{JHH}_{\mathrm{HH}}=3.3 \mathrm{~Hz}, 1 \mathrm{H}\right)$, $7.08\left(\mathrm{dt},{ }^{3} \mathrm{HH}=8.3,{ }^{4} \mathrm{JHH}_{\mathrm{HH}}=3.2 \mathrm{~Hz}, 1 \mathrm{H}\right), 7.50-7.56(\mathrm{~m}, 1 \mathrm{H}), 8.17-8.44(\mathrm{~m}$, $2 \mathrm{H}) \mathrm{ppm} .{ }^{13} \mathrm{C} \mathrm{NMR}\left(75.5 \mathrm{MHz}, \mathrm{CDCl}_{3}\right): \delta 23.3\left(\mathrm{CH}_{3}\right), 67.6(\mathrm{CH}), 123.5(\mathrm{CH})$ $124.5(\mathrm{CH}), 132.8(\mathrm{C}), 133.0(\mathrm{CH}), 137.0(\mathrm{CH}), 147.6(2 \mathrm{CH})$ ppm. HRMS $\left(\mathrm{ESI}^{+}, \mathrm{m} / \mathrm{z}\right)$ : calcd for $\left(\mathrm{C}_{9} \mathrm{H}_{12} \mathrm{NO}\right)^{+}(\mathrm{M}+\mathrm{H})^{+} 150.0913$, found: 150.0914 .

(E)-4-(Furan-2-yl)but-3-en-2-ol (1m). Red liquid (369 mg, 89\% yield). $R_{\mathrm{f}}$ (25\% EtOAc/hexane): 0.36. IR ( $\mathrm{NaCl}): 3347,2972,2927,2872,1656$, $1563,1490,1257,1150,1058,1013,963,798,737 \mathrm{~cm}^{-1} .{ }^{1} \mathrm{H}$ NMR $(300.13$ $\left.\mathrm{MHz}, \mathrm{CDCl}_{3}\right): \delta 1.30\left(\mathrm{~d},{ }^{3} \mathrm{JHH}_{\mathrm{HH}}=6.5 \mathrm{~Hz}, 3 \mathrm{H}\right), 3.20(\mathrm{br} \mathrm{s}, 1 \mathrm{H}), 4.35-4.44(\mathrm{~m}$, $1 \mathrm{H}), 6.13-6.23(\mathrm{~m}, 2 \mathrm{H}), 6.32(\mathrm{~m}, 2 \mathrm{H}), 7.30\left(\mathrm{~d},{ }^{3} \mathrm{JHH}_{\mathrm{H}}=1.2 \mathrm{~Hz}, 1 \mathrm{H}\right) \mathrm{ppm} .{ }^{13} \mathrm{C}$ $\operatorname{NMR}\left(75.5 \mathrm{MHz}, \mathrm{CDCl}_{3}\right): \delta 23.3\left(\mathrm{CH}_{3}\right), 68.1(\mathrm{CH}), 107.8(\mathrm{CH}), 111.2(\mathrm{CH})$, $117.5(\mathrm{CH}), 132.4(\mathrm{CH}), 141.8(\mathrm{CH}), 152.5(\mathrm{C}) \mathrm{ppm}$. HRMS $\left(\mathrm{ESI}^{+}, \mathrm{m} / \mathrm{z}\right)$ : calcd for $\left(\mathrm{C}_{8} \mathrm{H}_{10} \mathrm{NaO}_{2}\right)^{+}(\mathrm{M}+\mathrm{Na})^{+} 161.0573$, found: 161.0586 .

(E)-4-(Furan-3-yl)but-3-en-2-ol (1n). Dark orange liquid (361 mg, 87\%

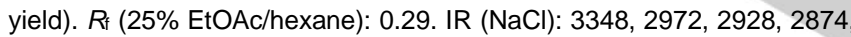
$1664,1508,1452,1370,1160,1138,1059,1023,965,848,779 \mathrm{~cm}^{-1} .{ }^{1} \mathrm{H}$ $\operatorname{NMR}\left(300.13 \mathrm{MHz}, \mathrm{CDCl}_{3}\right): \delta 1.28\left(\mathrm{~d},{ }^{3} \mathrm{JHH}_{\mathrm{HH}}=6.4 \mathrm{~Hz}, 3 \mathrm{H}\right), 3.26(\mathrm{br} \mathrm{s}, 1 \mathrm{H})$, 4.31-4.40 (m, 1H), $5.93\left(\mathrm{dd},{ }^{3} \mathrm{JHH}_{\mathrm{HH}}=15.8,{ }^{3} \mathrm{JHH}=6.3 \mathrm{~Hz}, 1 \mathrm{H}\right), 6.35\left(\mathrm{~d},{ }^{3} \mathrm{JHH}_{\mathrm{HH}}\right.$ $=15.8 \mathrm{~Hz}, 1 \mathrm{H}), 6.43-6.48(\mathrm{~s}, 1 \mathrm{H}), 7.30-7.34(\mathrm{~m}, 2 \mathrm{H}) \mathrm{ppm} .{ }^{13} \mathrm{C} \operatorname{NMR}(75.5$ $\left.\mathrm{MHz}, \mathrm{CDCl}_{3}\right): \delta 23.2\left(\mathrm{CH}_{3}\right), 68.4(\mathrm{CH}), 107.5(\mathrm{CH}), 118.8(\mathrm{CH}), 123.6(\mathrm{C})$, $133.3(\mathrm{CH}), 140.4(\mathrm{CH}), 143.4(\mathrm{CH}) \mathrm{ppm}$. HRMS $\left(\mathrm{ESI}^{+}, \mathrm{m} / \mathrm{z}\right)$ : calcd for $\left(\mathrm{C}_{8} \mathrm{H}_{10} \mathrm{NaO}_{2}\right)^{+}(\mathrm{M}+\mathrm{Na})^{+} 161.0573$, found: 161.0570 .

(E)-4-(Thiophen-2-yl)but-3-en-2-ol (10). Brown liquid $(423 \mathrm{mg}, 91 \%$ yield). $R_{\mathrm{f}}(25 \% \mathrm{EtOAc} / \mathrm{hexane}): 0.38$. IR ( $\left.\mathrm{NaCl}\right): 3372,2971,2925,2870$, $1648,1449,1369,1138,1058,957,853,695 \mathrm{~cm}^{-1}$. ${ }^{1} \mathrm{H}$ NMR $(300.13 \mathrm{MHz}$, $\left.\mathrm{CDCl}_{3}\right): \delta 1.35\left(\mathrm{~d},{ }^{3} \mathrm{JHH}_{\mathrm{HH}}=6.5 \mathrm{~Hz}, 3 \mathrm{H}\right), 3.53(\mathrm{~s}, 1 \mathrm{H}), 4.37-4.46(\mathrm{~m}, 1 \mathrm{H}), 6.11$ $\left(\mathrm{dd},{ }^{3} \mathrm{JHH}_{\mathrm{HH}}=15.7,{ }^{3} \mathrm{JHH}_{\mathrm{HH}}=6.2 \mathrm{~Hz}, 1 \mathrm{H}\right), 6.68\left(\mathrm{~d},{ }^{3} \mathrm{JHH}_{\mathrm{HH}}=15.7 \mathrm{~Hz}, 1 \mathrm{H}\right), 6.90-6.97$ $(\mathrm{m}, 2 \mathrm{H}), 7.10-7.16(\mathrm{~m}, 1 \mathrm{H}) \mathrm{ppm} .{ }^{13} \mathrm{C} \mathrm{NMR}\left(75.5 \mathrm{MHz}, \mathrm{CDCl}_{3}\right): \delta 23.2\left(\mathrm{CH}_{3}\right)$, $68.1(\mathrm{CH}), 122.2(\mathrm{CH}), 124.0(\mathrm{CH}), 125.5(\mathrm{CH}), 127.2(\mathrm{CH}), 133.2(\mathrm{CH})$, 141.8 (C) ppm. HRMS $\left(\mathrm{ESI}^{+}, \mathrm{m} / \mathrm{z}\right)$ : calcd for $\left(\mathrm{C}_{8} \mathrm{H}_{10} \mathrm{NaOS}\right)^{+}(\mathrm{M}+\mathrm{Na})^{+}$ 177.0345, found: 177.0333 .

(E)-4-(Thiophen-3-yl)but-3-en-2-ol (1p). White solid (328 mg, 71\% yield). $R_{\mathrm{f}}(25 \%$ EtOAc/hexane): 0.31. Mp: 59-60 으. IR ( $\mathrm{NaCl}): 3356,2971,2925$, $2871,1656,1450,1369,1159,1058,965,864,830,771 \mathrm{~cm}^{-1} .{ }^{1} \mathrm{H}$ NMR $\left(300.13 \mathrm{MHz}, \mathrm{CDCl}_{3}\right): \delta 1.36\left(\mathrm{~d},{ }^{3} \mathrm{JHH}=6.4 \mathrm{~Hz}, 3 \mathrm{H}\right), 1.75(\mathrm{~s}, 1 \mathrm{H}) 4.40-4.49$ $(\mathrm{m}, 1 \mathrm{H}), 6.11\left(\mathrm{dd},{ }^{3} J_{\mathrm{HH}}=15.9,{ }^{3} J_{\mathrm{HH}}=6.4 \mathrm{~Hz}, 1 \mathrm{H}\right), 6.58\left(\mathrm{dd},{ }^{3} \mathrm{JHH}_{\mathrm{HH}}=15.9\right.$, $\left.{ }^{4} J_{\mathrm{HH}}=0.6 \mathrm{~Hz}, 1 \mathrm{H}\right), 7.15\left(\mathrm{dd},{ }^{4} J_{\mathrm{HH}}=2.9,{ }^{4} J_{\mathrm{HH}}=1.2 \mathrm{~Hz}, 1 \mathrm{H}\right), 7.20\left(\mathrm{dd},{ }^{3} J_{\mathrm{HH}}\right.$ $\left.=5.1,{ }^{4} J_{H H}=1.1 \mathrm{~Hz}, 1 \mathrm{H}\right), 7.27\left(\mathrm{dd},{ }^{3} \mathrm{JHH}_{\mathrm{HH}}=5.0,{ }^{4} \mathrm{JHH}=2.9 \mathrm{~Hz}, 1 \mathrm{H}\right) \mathrm{ppm} \cdot{ }^{13} \mathrm{C}$ $\operatorname{NMR}\left(75.5 \mathrm{MHz}, \mathrm{CDCl}_{3}\right): \delta 23.5\left(\mathrm{CH}_{3}\right), 69.0(\mathrm{CH}), 122.3(\mathrm{CH}), 123.8(\mathrm{CH})$,
$125.1(\mathrm{CH}), 126.2(\mathrm{CH}), 133.6(\mathrm{CH}), 139.4(\mathrm{C}) \mathrm{ppm}$. HRMS $\left(\mathrm{ESI}^{+}, \mathrm{m} / \mathrm{z}\right)$ : calcd for $\left(\mathrm{C}_{8} \mathrm{H}_{10} \mathrm{NaOS}\right)^{+}(\mathrm{M}+\mathrm{Na})^{+} 177.0345$, found: 177.0333 .

\section{Typical procedure for the synthesis of amines $3 a-j, m-p$}

Amines 3a-j,m-p were synthesised following the procedure described by Schenck and Bosnich for amine $3 \mathrm{a}$ as follows: $:^{[14]}$ Solid $\mathrm{NaOH}$ (480 mg, 12 $\mathrm{mmol}$ ) was added in portions to a solution of the corresponding ketone $\mathbf{2 a}$ j, m-p $(1.2 \mathrm{mmol})$ and $\mathrm{NH}_{2} \mathrm{OH} \cdot \mathrm{HCl}(134 \mathrm{mg}, 1.92 \mathrm{mmol})$ in a mixture of $\mathrm{EtOH}(0.96 \mathrm{~mL})$ and water $(0.24 \mathrm{~mL})$. The mixture was refluxed overnight, cooled to room temperature and then acidified with a $\mathrm{HCl} 6 \mathrm{M}$ aqueous solution until pH 2. The mixture was extracted with $\mathrm{CH}_{2} \mathrm{Cl}_{2}(3 \times 15 \mathrm{~mL})$ and the combined organic phases dried over anhydrous $\mathrm{Na}_{2} \mathrm{SO}_{4}$, filtered and the solvent evaporated under reduced pressure, obtaining the corresponding oxime intermediate, which was further used without additional purification. Then, zinc dust ( $393 \mathrm{mg}, 6 \mathrm{mmol}$ ) was added in portions to an ice-cooled solution of the so-obtained oxime intermediate in $\mathrm{EtOH}(0.8 \mathrm{~mL})$ and glacial acetic acid $(0.8 \mathrm{~mL})$. The mixture was allowed to warm up to room temperature and then gently warmed and stirred on a steam bath for $2 \mathrm{~h}$. Afterwards, rests of zinc dust were filtered-off and the solvent evaporated under reduced pressure. The residue was dissolved in a $\mathrm{HCl} 6 \mathrm{M}$ aqueous solution $(10 \mathrm{~mL})$ and washed with $\mathrm{CH}_{2} \mathrm{Cl}_{2}(3 \times 15 \mathrm{~mL})$. Then, the aqueous phase was treated with a $\mathrm{NaOH} 10 \mathrm{M}$ aqueous solution until pH 12. The resulting aqueous layer was extracted with $\mathrm{CH}_{2} \mathrm{Cl}_{2}(3 \times 15$ $\mathrm{mL})$, and the combined organic phases were washed with brine $(5 \mathrm{~mL})$, dried over anhydrous $\mathrm{Na}_{2} \mathrm{SO}_{4}$ and filtered. After evaporation of the solvent under reduced pressure, the corresponding amines 3a-d,f-j, o-p were obtained with high purity (21-54\% yield), except amines $\mathbf{3 e}, \mathbf{3 m}$ and $\mathbf{3 n}$ that were additionally purified by column chromatography on silica gel $(5 \%$ $\mathrm{NH}_{3} / \mathrm{MeOH}, 21-54 \%$ yield).

(E)-4-Phenylbut-3-en-2-amine (3a). Pale yellow oil (92 mg $52 \%$ yield). $R_{\mathrm{f}}$ ( $\left.5 \% \mathrm{NH}_{3} / \mathrm{MeOH}\right): 0.62$. IR ( $\left.\mathrm{NaCl}\right): 3362,3287,2963,1948,1878,1805$, 1493, 1449, 1369, 967, 748, $694 \mathrm{~cm}^{-1} .{ }^{1} \mathrm{H}$ NMR $\left(300.13 \mathrm{MHz}, \mathrm{CDCl}_{3}\right): \delta$ $1.25\left(\mathrm{~d},{ }^{3} \mathrm{JHH}_{\mathrm{H}}=6.5 \mathrm{~Hz}, 3 \mathrm{H}\right), 1.67(\mathrm{br} \mathrm{s}, 2 \mathrm{H}), 3.61-3.70(\mathrm{~m}, 1 \mathrm{H}), 6.20(\mathrm{dd}$, $\left.{ }^{3} \mathrm{JHH}_{\mathrm{HH}}=15.8,{ }^{3} \mathrm{JHH}=6.6 \mathrm{~Hz}, 1 \mathrm{H}\right), 6.45\left(\mathrm{~d},{ }^{3} \mathrm{~J}_{\mathrm{HH}}=15.8 \mathrm{~Hz}, 1 \mathrm{H}\right), 7.17-7.25(\mathrm{~m}$, $1 \mathrm{H})$, 7.26-7.39 (m, 4H) ppm. ${ }^{13} \mathrm{C} \mathrm{NMR}\left(75.5 \mathrm{MHz}, \mathrm{CDCl}_{3}\right): \delta 23.9\left(\mathrm{CH}_{3}\right)$, $49.3(\mathrm{CH}), 126.3(2 \mathrm{CH}), 127.3(\mathrm{CH}), 127.8(\mathrm{CH}), 128.6(2 \mathrm{CH}), 136.2(\mathrm{CH})$, $137.2(\mathrm{C}) \mathrm{ppm}$. HRMS $\left(\mathrm{ESI}^{+}, \mathrm{m} / \mathrm{z}\right)$ : calcd for $\left(\mathrm{C}_{10} \mathrm{H}_{14} \mathrm{~N}\right)^{+}(\mathrm{M}+\mathrm{H})^{+}$148.1121, found: 148.1119 .

(E)-4-(4-Methoxyphenyl)but-3-en-2-amine (3b). Pale yellow wax (115 $\mathrm{mg}, 54 \%$ yield). $R_{\mathrm{f}}\left(5 \% \mathrm{NH}_{3} / \mathrm{MeOH}\right): 0.53$. IR (NaCl): 3417, 3945, 2964, 2837, 1608, 1512, 1248, $737 \mathrm{~cm}^{-1}$. ${ }^{1} \mathrm{H}$ NMR $\left(300.13 \mathrm{MHz}, \mathrm{CDCl}_{3}\right): \delta 1.24$ $\left(\mathrm{d},{ }^{3} \mathrm{JHH}_{\mathrm{HH}}=6.5 \mathrm{~Hz}, 3 \mathrm{H}\right), 2.06(\mathrm{br} \mathrm{s}, 2 \mathrm{H}), 3.63(\mathrm{~m}, 1 \mathrm{H}), 3.79(\mathrm{~s}, 3 \mathrm{H}), 6.06(\mathrm{dd}$, $\left.{ }^{3} J_{\mathrm{HH}}=15.9 \mathrm{~Hz},{ }^{3} \mathrm{JHH}_{\mathrm{HH}}=6.8 \mathrm{~Hz}, 1 \mathrm{H}\right), 6.40\left(\mathrm{~d},{ }^{3} \mathrm{~J}_{\mathrm{HH}}=15.9 \mathrm{~Hz}, 1 \mathrm{H}\right), 6.81-6.86$ $(\mathrm{m}, 2 \mathrm{H}), 7.27-7.31(\mathrm{~m}, 2 \mathrm{H})$ ppm. ${ }^{13} \mathrm{C} \mathrm{NMR}\left(75.5 \mathrm{MHz}, \mathrm{CDCl}_{3}\right)$ : $\delta 23.9\left(\mathrm{CH}_{3}\right)$, $49.5(\mathrm{CH}), 55.4\left(\mathrm{CH}_{3}\right), 114.1(2 \mathrm{CH}), 127.5(\mathrm{CH}), 127.5(2 \mathrm{CH}), 130.0(\mathrm{C})$, $133.9(\mathrm{CH}), 159.1$ (C) ppm. HRMS $\left(\mathrm{ESI}^{+}, \mathrm{m} / \mathrm{z}\right)$ : calcd for $\left(\mathrm{C}_{11} \mathrm{H}_{16} \mathrm{NO}\right)^{+}$ $(\mathrm{M}+\mathrm{H})^{+}$178.1226, found: 178.1231 .

(E)-4-(4-Chlorophenyl)but-3-en-2-amine (3c). Yellow wax (92 mg, 42\% yield). $R_{\mathrm{f}}\left(5 \% \mathrm{NH}_{3} / \mathrm{MeOH}\right): 0.64 . \mathrm{IR}(\mathrm{NaCl}): 3356,3282,2965,2925,1491$, 1092, $808 \mathrm{~cm}^{-1} .{ }^{1} \mathrm{H}$ NMR $\left(300.13 \mathrm{MHz}, \mathrm{CDCl}_{3}\right): \delta 1.21\left(\mathrm{~d},{ }^{3} \mathrm{JHH}=6.5 \mathrm{~Hz}\right.$, $3 \mathrm{H}), 2.04(\mathrm{br} \mathrm{s}, 2 \mathrm{H}), 3.59-3.68(\mathrm{~m}, 1 \mathrm{H}), 6.14\left(\mathrm{dd},{ }^{3} \mathrm{JHH}_{\mathrm{HH}}=15.9,{ }^{3} \mathrm{JHH}=6.5\right.$ $\mathrm{Hz}, 1 \mathrm{H}), 6.37\left(\mathrm{~d},{ }^{3} \mathrm{HHH}_{\mathrm{HH}} 15.9 \mathrm{~Hz}, 1 \mathrm{H}\right), 7.23(\mathrm{~s}, 4 \mathrm{H}) \mathrm{ppm} .{ }^{13} \mathrm{C} \mathrm{NMR}(75.5$ $\left.\mathrm{MHz}, \mathrm{CDCl}_{3}\right): \delta 23.8\left(\mathrm{CH}_{3}\right), 49.2(\mathrm{CH}), 126.7(\mathrm{CH}), 127.5(2 \mathrm{CH}), 128.6$ (2CH), $132.8(\mathrm{C}), 135.7(\mathrm{C}), 136.7(\mathrm{CH}) \mathrm{ppm}$. HRMS (ESl+, $\mathrm{m} / \mathrm{z})$ : calcd for $\left(\mathrm{C}_{10} \mathrm{H}_{13} \mathrm{CIN}\right)^{+}(\mathrm{M}+\mathrm{H})^{+}$182.0731, found: 182.0739 .

For internal use, please do not delete. Submitted_Manuscript 
(E)-4-(4-Fluorophenyl)but-3-en-2-amine (3d). Yellow oil (75 mg, 38\% yield). $R_{\mathrm{f}}\left(5 \% \mathrm{NH}_{3} / \mathrm{MeOH}\right): 0.60$. IR ( $\left.\mathrm{NaCl}\right): 3355,3287,2967,2925,1928$, 1602, 1509, 1226, 1158, 969, $817 \mathrm{~cm}^{-1} .{ }^{1} \mathrm{H}$ NMR $\left(300.13 \mathrm{MHz}, \mathrm{CDCl}_{3}\right): \delta$ $1.10\left(\mathrm{~d},{ }^{3} \mathrm{HHH}_{\mathrm{H}}=6.5 \mathrm{~Hz}, 3 \mathrm{H}\right), 1.70(\mathrm{br} \mathrm{s}, 2 \mathrm{H}), 3.49(\mathrm{~m}, 1 \mathrm{H}), 5.97\left(\mathrm{dd},{ }^{3} \mathrm{HHH}=\right.$ $\left.15.9,{ }^{3} \mathrm{JHH}_{\mathrm{HH}}=6.5 \mathrm{~Hz}, 1 \mathrm{H}\right), 6.27\left(\mathrm{~d},{ }^{3} \mathrm{~J}_{\mathrm{HH}}=15.9 \mathrm{~Hz}, 1 \mathrm{H}\right), 6.80-6.89(\mathrm{~m}, 2 \mathrm{H})$, 7.13-7.20 (m, 2H) ppm. ${ }^{13} \mathrm{C}$ NMR $\left(75.5 \mathrm{MHz}, \mathrm{CDCl}_{3}\right): \delta 23.5\left(\mathrm{CH}_{3}\right), 48.9$ $(\mathrm{CH}), 115.1(\mathrm{~d}, J=21.6 \mathrm{~Hz}, 2 \mathrm{CH}), 126.3(\mathrm{CH}), 127.4(\mathrm{~d}, J=7.8 \mathrm{~Hz}, 2 \mathrm{CH})$, $133.1(\mathrm{~d}, J=3.3 \mathrm{~Hz}, \mathrm{C}), 135.6(\mathrm{~d}, J=2.2 \mathrm{~Hz}, \mathrm{CH}), 161.8(\mathrm{~d}, J=246.1 \mathrm{~Hz}$, C) ppm. ${ }^{19} \mathrm{~F} \mathrm{NMR}\left(282 \mathrm{MHz}, \mathrm{CDCl}_{3}\right): \delta-115.0 \mathrm{ppm}$. HRMS $\left(\mathrm{ESI}^{+}, \mathrm{m} / \mathrm{z}\right)$ : calcd for $\left(\mathrm{C}_{10} \mathrm{H}_{13} \mathrm{FN}\right)^{+}(\mathrm{M}+\mathrm{H})^{+}$166.1027, found: 166.1029 .

(E)-4-(4-Bromophenyl)but-3-en-2-amine (3e). Yellow oil (58 mg, 21\% yield). $R_{\mathrm{f}}\left(5 \% \mathrm{NH}_{3} / \mathrm{MeOH}\right): 0.64$. IR ( $\left.\mathrm{NaCl}\right): 3357,3288,2962,2925,1487$, $1359,1176,1008,967,809 \mathrm{~cm}^{-1} .{ }^{1} \mathrm{H}$ NMR $\left(300.13 \mathrm{MHz}, \mathrm{CDCl}_{3}\right): \delta 1.24(\mathrm{~d}$, $\left.{ }^{3} J_{H H}=6.5 \mathrm{~Hz}, 3 \mathrm{H}\right), 1.61(\mathrm{br} \mathrm{s}, 2 \mathrm{H}), 3.60-3.69(\mathrm{~m}, 1 \mathrm{H}), 6.18\left(\mathrm{dd},{ }^{3} \mathrm{HHH}_{\mathrm{HH}}=15.9\right.$, $\left.{ }^{3} \mathrm{HHH}_{\mathrm{HH}}=6.5 \mathrm{~Hz}, 1 \mathrm{H}\right), 6.39\left(\mathrm{~d},{ }^{3} \mathrm{JHH}_{\mathrm{HH}}=15.9 \mathrm{~Hz}, 1 \mathrm{H}\right), 7.19-7.23(\mathrm{~m}, 2 \mathrm{H}), 7.38$ $7.43(\mathrm{~m}, 2 \mathrm{H})$ ppm. ${ }^{13} \mathrm{C} \mathrm{NMR}\left(75.5 \mathrm{MHz}, \mathrm{CDCl}_{3}\right): \delta 24.0\left(\mathrm{CH}_{3}\right), 49.3(\mathrm{CH})$, $121.0(\mathrm{C}), 126.8(\mathrm{CH}), 127.9(2 \mathrm{CH}), 131.7(2 \mathrm{CH}), 136.3(\mathrm{C}), 137.1(\mathrm{CH})$ ppm. HRMS $\left(\mathrm{ESI}^{+}, \mathrm{m} / \mathrm{z}\right)$ : calcd for $\left(\mathrm{C}_{10} \mathrm{H}_{13} \mathrm{BrN}\right)^{+}(\mathrm{M}+\mathrm{H})^{+} 226.0226$, found: 226.0221.

(E)-4-(3-Methoxyphenyl)but-3-en-2-amine (3f). Yellow oil (94 mg, 44\% yield). $R_{\mathrm{f}}\left(5 \% \mathrm{NH}_{3} / \mathrm{MeOH}\right): 0.58$. IR ( $\left.\mathrm{NaCl}\right): 3358,3290,2962,2835,1598$, $1464,1156,1047,970,779,691 \mathrm{~cm}^{-1} .{ }^{1} \mathrm{H}$ NMR $\left(300.13 \mathrm{MHz}, \mathrm{CDCl}_{3}\right): \delta$ $1.21\left(\mathrm{~d},{ }^{3} \mathrm{JHH}=6.5 \mathrm{~Hz}, 3 \mathrm{H}\right), 1.97(\mathrm{br} \mathrm{s}, 2 \mathrm{H}), 3.62(\mathrm{~m}, 1 \mathrm{H}), 3.76(\mathrm{~s}, 3 \mathrm{H}), 6.16$ $\left(\mathrm{dd},{ }^{3} \mathrm{JHH}_{\mathrm{HH}}=15.9,{ }^{3} \mathrm{JHH}=6.6 \mathrm{~Hz}, 1 \mathrm{H}\right), 6.39\left(\mathrm{~d},{ }^{3} \mathrm{JHH}=15.9 \mathrm{~Hz}, 1 \mathrm{H}\right), 6.74(\mathrm{ddd}$, $\left.{ }^{3} J_{\mathrm{HH}}=8.2,{ }^{4} \mathrm{~J}_{\mathrm{HH}}=2.6,{ }^{4} \mathrm{~J}_{\mathrm{HH}}=1.0 \mathrm{~Hz}, 1 \mathrm{H}\right), 6.88$ (apparent t, ${ }^{4} \mathrm{JHH}_{\mathrm{HH}}=2.6 \mathrm{~Hz}$, $1 \mathrm{H}), 6.93\left(\mathrm{~d},{ }^{3} \mathrm{~J}_{\mathrm{HH}}=7.8 \mathrm{~Hz}, 1 \mathrm{H}\right), 7.18\left(\right.$ apparent t, $\left.{ }^{3} \mathrm{HH}=7.8 \mathrm{~Hz}, 1 \mathrm{H}\right) \mathrm{ppm}$. ${ }^{13} \mathrm{C}$ NMR $\left(75.5 \mathrm{MHz}, \mathrm{CDCl}_{3}\right)$ : $\delta 23.7\left(\mathrm{CH}_{3}\right), 49.2(\mathrm{CH}), 55.1\left(\mathrm{CH}_{3}\right), 111.5$ $(\mathrm{CH}), 112.9(\mathrm{CH}), 118.9(\mathrm{CH}), 127.7(\mathrm{CH}), 129.5(\mathrm{CH}), 136.3(\mathrm{CH}), 138.6$ (C), 159.7 (C) ppm. HRMS $\left(\mathrm{ESI}^{+}, \mathrm{m} / \mathrm{z}\right)$ : calcd for $\left(\mathrm{C}_{11} \mathrm{H}_{16} \mathrm{NO}\right)^{+}(\mathrm{M}+\mathrm{H})^{+}$ 178.1226, found: 178.1224 .

(E)-4-(2-Methoxyphenyl)but-3-en-2-amine (3g). Brown oil (92 mg, 43\% yield). $R_{\mathrm{f}}\left(5 \% \mathrm{NH}_{3} / \mathrm{MeOH}\right): 0.54$. IR ( $\left.\mathrm{NaCl}\right): 3357,3289,2962,2837,1935$, $1899,1798,1597,1489,1243,1028,975,752 \mathrm{~cm}^{-1}$. ${ }^{1} \mathrm{H} \mathrm{NMR}(300.13 \mathrm{MHz}$, $\left.\mathrm{CDCl}_{3}\right): \delta 1.23\left(\mathrm{~d},{ }^{3} \mathrm{JHH}=6.5 \mathrm{~Hz}, 3 \mathrm{H}\right), 3.59-3.67(\mathrm{~m}, 1 \mathrm{H}), 3.81(\mathrm{~s}, 3 \mathrm{H}), 6.19$ $\left(\mathrm{dd},{ }^{3} \mathrm{HHH}=16.0,{ }^{3} \mathrm{JHH}_{\mathrm{HH}}=6.8 \mathrm{~Hz}, 1 \mathrm{H}\right), 6.74-6.93(\mathrm{~m}, 3 \mathrm{H}), 7.18\left(\mathrm{ddd},{ }^{3} \mathrm{JHH}_{\mathrm{HH}}=\right.$ $\left.9.1,{ }^{3} J_{\mathrm{HH}}=7.5,{ }^{4} \mathrm{JHH}_{\mathrm{HH}}=1.7 \mathrm{~Hz}, 1 \mathrm{H}\right), 7.42\left(\mathrm{dd},{ }^{3}{ }^{\mathrm{HH}}=7.5,{ }^{4} \mathrm{JHH}=1.7 \mathrm{~Hz}, 1 \mathrm{H}\right)$ ppm. ${ }^{13} \mathrm{C} \mathrm{NMR}\left(75.5 \mathrm{MHz}, \mathrm{CDCl}_{3}\right): \delta 23.8\left(\mathrm{CH}_{3}\right), 49.5(\mathrm{CH}), 55.4\left(\mathrm{CH}_{3}\right)$, $110.7(\mathrm{CH}), 120.6(\mathrm{CH}), 122.4(\mathrm{CH}), 126.1(\mathrm{C}), 126.6(\mathrm{CH}), 128.3(\mathrm{CH})$, $137.0(\mathrm{CH}), 156.5$ (C) ppm. HRMS $\left(\mathrm{ESI}^{+}, \mathrm{m} / \mathrm{z}\right)$ : calcd for $\left(\mathrm{C}_{11} \mathrm{H}_{16} \mathrm{NO}\right)^{+}$ $(\mathrm{M}+\mathrm{H})^{+}$178.1226, found: 178.1222 .

(E)-4-(3-Fluorophenyl)but-3-en-2-amine (3h). Yellow oil (44 mg, 22\% yield). $R_{\mathrm{f}}\left(5 \% \mathrm{NH}_{3} / \mathrm{MeOH}\right): 0.61$. IR ( $\left.\mathrm{NaCl}\right): 3351,3276,2961,2925,2856$, 1936, 1858, 1586, 1488, 1448, 1265, 1142, 969, $783 \mathrm{~cm}^{-1} .{ }^{1} \mathrm{H}$ NMR $\left(300.13 \mathrm{MHz}, \mathrm{CDCl}_{3}\right): \delta 1.16\left(\mathrm{~d},{ }^{3} \mathrm{JHH}_{\mathrm{HH}}=6.5 \mathrm{~Hz}, 3 \mathrm{H}\right), 1.55(\mathrm{br} \mathrm{s}, 2 \mathrm{H}), 3.52-$ $3.61(\mathrm{~m}, 1 \mathrm{H}), 6.12\left(\mathrm{dd},{ }^{3} \mathrm{JHH}_{\mathrm{HH}}=15.9,{ }^{3} \mathrm{JHH}_{\mathrm{HH}}=6.5 \mathrm{~Hz}, 1 \mathrm{H}\right), 6.33\left(\mathrm{~d},{ }^{3} \mathrm{JHH}_{\mathrm{HH}}=15.9\right.$ $\mathrm{Hz}, 1 \mathrm{H}$ ), 6.81 (apparent tdd, $J=8.3, J=2.6, J=1.0 \mathrm{~Hz}, 1 \mathrm{H}$ ), 6.97 (dt, $J=$ $10.3, J=2.2 \mathrm{~Hz}, 1 \mathrm{H}), 7.03(\mathrm{~d}, J=7.7 \mathrm{~Hz}, 1 \mathrm{H}), 7.12-7.19(\mathrm{~m}, 1 \mathrm{H}) \mathrm{ppm} .{ }^{13} \mathrm{C}$ $\operatorname{NMR}\left(75.5 \mathrm{MHz}, \mathrm{CDCl}_{3}\right): \delta 23.9\left(\mathrm{CH}_{3}\right), 49.2(\mathrm{CH}), 112.7(\mathrm{~d}, J=21.8 \mathrm{~Hz}$, $\mathrm{CH}), 114.0(\mathrm{~d}, J=21.4 \mathrm{~Hz}, \mathrm{CH}), 122.2(\mathrm{~d}, J=2.7 \mathrm{~Hz}, \mathrm{CH}), 126.8(\mathrm{~d}, J=$ $2.5 \mathrm{~Hz}, \mathrm{CH}), 130.0$ (d, $J=8.5 \mathrm{~Hz}, \mathrm{CH}), 137.6(\mathrm{CH}), 139.7$ (d, $J=7.8 \mathrm{~Hz}$, C), 163.1 (d, $J=245.2 \mathrm{~Hz}, \mathrm{C}) \mathrm{ppm} .{ }^{19} \mathrm{~F} \mathrm{NMR}\left(282 \mathrm{MHz}, \mathrm{CDCl}_{3}\right): \delta-113.6$ ppm. HRMS $\left(\mathrm{ESI}^{+}, \mathrm{m} / \mathrm{z}\right)$ : calcd for $\left(\mathrm{C}_{10} \mathrm{H}_{13} \mathrm{FN}\right)^{+}(\mathrm{M}+\mathrm{H})^{+} 166.1027$, found: 166.1014 .

(E)-4-(2-Fluorophenyl)but-3-en-2-amine (3i). Pale yellow wax (52 mg, $26 \%$ yield). $R_{\mathrm{f}}\left(5 \% \mathrm{NH}_{3} / \mathrm{MeOH}\right): 0.64$. IR ( $\left.\mathrm{NaCl}\right): 3356,3269,2963,2925$, $2855,1946,1912,1799,1581,1488,1455,1375,1229,970,755 \mathrm{~cm}^{-1} .{ }^{1} \mathrm{H}$ $\operatorname{NMR}\left(300.13 \mathrm{MHz}, \mathrm{CDCl}_{3}\right): \delta 1.25\left(\mathrm{~d},{ }^{3} \mathrm{JHH}_{\mathrm{HH}}=6.5 \mathrm{~Hz}, 3 \mathrm{H}\right), 1.61(\mathrm{br} \mathrm{s}, 2 \mathrm{H})$,
3.61-3.72 (m, 1H), $6.27\left(\mathrm{dd},{ }^{3} \mathrm{JHH}_{\mathrm{HH}} 16.0,{ }^{3} \mathrm{JHH}_{\mathrm{HH}}=6.7 \mathrm{~Hz}, 1 \mathrm{H}\right), 6.61\left(\mathrm{~d},{ }^{3} \mathrm{JHH}_{\mathrm{HH}}\right.$ $=16.0 \mathrm{~Hz}, 1 \mathrm{H}), 6.96-7.10(\mathrm{~m}, 2 \mathrm{H}), 7.13-7.20(\mathrm{~m}, 1 \mathrm{H}), 7.43($ apparent td, $J$ $=7.7, J=1.9 \mathrm{~Hz}, 1 \mathrm{H}) \mathrm{ppm} .{ }^{13} \mathrm{C} \mathrm{NMR}\left(75.5 \mathrm{MHz}, \mathrm{CDCl}_{3}\right): \delta 23.8\left(\mathrm{CH}_{3}\right)$, $49.8(\mathrm{CH}), 115.8$ (d, $J=22.3, \mathrm{CH}), 120.6(\mathrm{~d}, J=3.5, \mathrm{CH}), 124.2$ (d, $J=3.3$ $\mathrm{Hz}, \mathrm{CH}), 125.0$ (d, $J=12.6 \mathrm{~Hz}, \mathrm{C}), 127.4(\mathrm{~d}, J=3.7 \mathrm{~Hz}, \mathrm{CH}), 128.7$ (d, $J$ $=8.3 \mathrm{~Hz}, \mathrm{CH}), 138.6(\mathrm{~d}, J=4.3 \mathrm{~Hz}, \mathrm{CH}), 160.3(\mathrm{~d}, J=249.1 \mathrm{~Hz}, \mathrm{C}) \mathrm{ppm}$. ${ }^{19} \mathrm{~F}$ NMR $\left(282 \mathrm{MHz}, \mathrm{CDCl}_{3}\right): \delta-118.5 \mathrm{ppm}$. HRMS $\left(\mathrm{ESI}^{+}, \mathrm{m} / \mathrm{z}\right)$ : calcd for $\left(\mathrm{C}_{10} \mathrm{H}_{13} \mathrm{FN}\right)^{+}(\mathrm{M}+\mathrm{H})^{+}$166.1027, found: 166.1028 .

(E)-4-( $m$-Tolyl)but-3-en-2-amine (3j). Yellow oil (81 mg, $42 \%$ yield). $R_{\mathrm{f}}$ (5\% NH $3 / \mathrm{MeOH}): 0.58$. IR ( $\mathrm{NaCl}): 3354,3288,2966,2922,1604,1454$, $1373,968,778,695 \mathrm{~cm}^{-1} .{ }^{1} \mathrm{H}$ NMR $\left(300.13 \mathrm{MHz}, \mathrm{CDCl}_{3}\right): \delta 1.25\left(\mathrm{~d},{ }^{3} \mathrm{JHH}_{\mathrm{H}}=\right.$ $6.5 \mathrm{~Hz}, 3 \mathrm{H}), 1.79(\mathrm{br} \mathrm{s}, 2 \mathrm{H}), 2.34(\mathrm{~s}, 3 \mathrm{H}), 3.61-3.70(\mathrm{~m}, 1 \mathrm{H}), 6.19\left(\mathrm{dd},{ }^{3} \mathrm{JHH}\right.$ $\left.=15.9,{ }^{3} \mathrm{~J}_{\mathrm{HH}}=6.7 \mathrm{~Hz}, 1 \mathrm{H}\right), 6.43\left(\mathrm{dd},{ }^{3} \mathrm{JHH}_{\mathrm{HH}}=15.9,{ }^{4} \mathrm{JHH}=1.2 \mathrm{~Hz}, 1 \mathrm{H}\right), 6.99-$ $7.23(\mathrm{~m}, 4 \mathrm{H}) \mathrm{ppm} .{ }^{13} \mathrm{C} \mathrm{NMR}(75.5 \mathrm{MHz}, \mathrm{CDCl}): \delta 21.5\left(\mathrm{CH}_{3}\right), 23.9\left(\mathrm{CH}_{3}\right)$, $49.4(\mathrm{CH}), 123.5(\mathrm{CH}), 127.0(\mathrm{CH}), 128.0(\mathrm{CH}), 128.1(\mathrm{CH}), 128.5(\mathrm{CH})$, $136.0(\mathrm{CH}), 137.2(\mathrm{C}), 138.1$ (C) ppm. HRMS (ESl $\left.{ }^{+}, \mathrm{m} / \mathrm{z}\right)$ : calcd for $\left(\mathrm{C}_{11} \mathrm{H}_{16} \mathrm{~N}\right)^{+}(\mathrm{M}+\mathrm{H})^{+} 162.1277$, found: 162.1278 .

(E)-4-(Furan-2-yl)but-3-en-2-amine (3m). Yellow oil (64 mg, 39\% yield). $R_{\mathrm{f}}\left(5 \% \mathrm{NH}_{3} / \mathrm{MeOH}\right): 0.61$. IR ( $\left.\mathrm{NaCl}\right): 3354,3287,2966,2927,2870,1651$, $1594,1453,1374,1255,1012,964,926,884,800,735 \mathrm{~cm}^{-1} .{ }^{1} \mathrm{H}$ NMR $\left(300.13 \mathrm{MHz}, \mathrm{CDCl}_{3}\right): \delta 1.19\left(\mathrm{~d},{ }^{3} \mathrm{JHH}_{\mathrm{HH}}=6.5 \mathrm{~Hz}, 3 \mathrm{H}\right), 1.55(\mathrm{br} \mathrm{s}, 2 \mathrm{H}), 3.53-$ $3.62(\mathrm{~m}, 1 \mathrm{H}), 6.08-6.18(\mathrm{~m}, 2 \mathrm{H}), 6.26\left(\mathrm{~d},{ }^{3} \mathrm{JHH}_{\mathrm{HH}}=16.0 \mathrm{~Hz}, 1 \mathrm{H}\right), 6.31(\mathrm{dd}$, $\left.{ }^{3} \mathrm{JHH}_{\mathrm{HH}}=3.3,{ }^{3} \mathrm{JHH}=1.9 \mathrm{~Hz}, 1 \mathrm{H}\right), 7.29\left(\mathrm{~d},{ }^{3} \mathrm{HHH}_{\mathrm{HH}} 1.8 \mathrm{~Hz}, 1 \mathrm{H}\right) \mathrm{ppm} .{ }^{13} \mathrm{C} \mathrm{NMR}$ (75.5 MHz, $\left.\mathrm{CDCl}_{3}\right): \delta 23.9\left(\mathrm{CH}_{3}\right), 49.0(\mathrm{CH}), 107.2(\mathrm{CH}), 111.2(\mathrm{CH}), 116.4$ $(\mathrm{CH}), 135.1(\mathrm{CH}), 141.6(\mathrm{CH}), 152.8(\mathrm{C}) \mathrm{ppm}$. HRMS $\left(\mathrm{ESI}^{+}, \mathrm{m} / \mathrm{z}\right)$ : calcd for $\left(\mathrm{C}_{8} \mathrm{H}_{12} \mathrm{NO}\right)^{+}(\mathrm{M}+\mathrm{H})^{+} 138.0913$, found: 138.0910 .

(E)-4-(Furan-3-yl)but-3-en-2-amine (3n). Yellow oil (68 mg, 41\% yield). $R_{\mathrm{f}}\left(5 \% \mathrm{NH}_{3} / \mathrm{MeOH}\right): 0.52$. IR $(\mathrm{NaCl}): 3411,3405,2970,2929,2872,1658$, $1508,1452,1374,1160,1073,1023,967,871,782,731,596 \mathrm{~cm}^{-1} .{ }^{1} \mathrm{H}$ $\operatorname{NMR}\left(300.13 \mathrm{MHz}, \mathrm{CDCl}_{3}\right): \delta 1.21\left(\mathrm{~d},{ }^{3} \mathrm{JHH}_{\mathrm{HH}}=6.5 \mathrm{~Hz}, 3 \mathrm{H}\right), 1.55$ (br s, $\left.2 \mathrm{H}\right)$, 3.56-3.65 (m, 1H), $5.93\left(\mathrm{dd},{ }^{3} \mathrm{JHH}_{\mathrm{HH}}=15.8,{ }^{3} \mathrm{JHH}=6.6 \mathrm{~Hz}, 1 \mathrm{H}\right), 6.32\left(\mathrm{~d},{ }^{3} \mathrm{JHH}_{\mathrm{HH}}\right.$ $=15.8 \mathrm{~Hz}, 1 \mathrm{H}), 6.50\left(\mathrm{~d},{ }^{3} \mathrm{JHH}_{\mathrm{HH}}=1.7 \mathrm{~Hz}, 1 \mathrm{H}\right), 7.35(\mathrm{~m}, 1 \mathrm{H}), 7.37(\mathrm{~s}, 1 \mathrm{H}) \mathrm{ppm}$. ${ }^{13} \mathrm{C}$ NMR $\left(75.5 \mathrm{MHz}, \mathrm{CDCl}_{3}\right): \delta 24.0\left(\mathrm{CH}_{3}\right), 49.3(\mathrm{CH}), 107.7(\mathrm{CH}), 117.6$ $(\mathrm{CH}), 124.1(\mathrm{C}), 136.0(\mathrm{CH}), 140.2(\mathrm{CH}), 143.6(\mathrm{CH}) \mathrm{ppm}$. HRMS $\left(\mathrm{ESI}^{+}\right.$, $\mathrm{m} / \mathrm{z})$ : calcd for $\left(\mathrm{C}_{8} \mathrm{H}_{12} \mathrm{NO}\right)^{+}(\mathrm{M}+\mathrm{H})^{+}$138.0913, found: 138.0915 .

(E)-4-(Thiophen-2-yl)but-3-en-2-amine (30). Yellow oil $(73 \mathrm{mg}, 40 \%$ yield). $R_{\mathrm{f}}\left(5 \% \mathrm{NH}_{3} / \mathrm{MeOH}\right): 0.70$. IR ( $\left.\mathrm{NaCl}\right): 3356,3289,2959,2925,2855$, 1650, 1594, 1454, 1376, 957, 853, 810, $696 \mathrm{~cm}^{-1}$. ${ }^{1} \mathrm{H}$ NMR $(300.13 \mathrm{MHz}$, $\left.\mathrm{CDCl}_{3}\right): \delta 1.24\left(\mathrm{~d},{ }^{3} \mathrm{HHH}_{\mathrm{H}}=6.6 \mathrm{~Hz}, 3 \mathrm{H}\right), 1.58(\mathrm{br} \mathrm{s}, 2 \mathrm{H}), 3.58-3.67(\mathrm{~m}, 1 \mathrm{H})$, $6.06\left(\mathrm{dd},{ }^{3} \mathrm{JHH}=15.7,{ }^{3} \mathrm{JHH}_{\mathrm{HH}}=6.6 \mathrm{~Hz}, 1 \mathrm{H}\right), 6.60\left(\mathrm{~d},{ }^{3} \mathrm{~J}_{\mathrm{HH}}=15.7 \mathrm{~Hz}, 1 \mathrm{H}\right), 6.88-$ $6.97(\mathrm{~m}, 2 \mathrm{H}), 7.12\left(\mathrm{~d},{ }^{3} \mathrm{JHH}_{\mathrm{HH}}=4.9 \mathrm{~Hz}, 1 \mathrm{H}\right) \mathrm{ppm} .{ }^{13} \mathrm{C} \mathrm{NMR}\left(75.5 \mathrm{MHz}, \mathrm{CDCl}_{3}\right)$ : $\delta 23.9\left(\mathrm{CH}_{3}\right), 49.2(\mathrm{CH}), 121.3(\mathrm{CH}), 123.9(\mathrm{CH}), 125.3(\mathrm{CH}), 127.4(\mathrm{CH})$, $136.1(\mathrm{CH}), 142.5(\mathrm{C}) \mathrm{ppm}$. HRMS $\left(\mathrm{ESI}^{+}, \mathrm{m} / \mathrm{z}\right)$ : calcd for $\left(\mathrm{C}_{8} \mathrm{H}_{12} \mathrm{NS}\right)^{+}$ $(\mathrm{M}+\mathrm{H})^{+} 154.0685$, found: 154.0684 .

(E)-4-(Thiophen-3-yl)but-3-en-2-amine (3p). Yellow oil $(63 \mathrm{mg}, 34 \%$ yield). $R_{\mathrm{f}}\left(5 \% \mathrm{NH}_{3} / \mathrm{MeOH}\right): 0.60 . \mathrm{IR}(\mathrm{NaCl}): 3405,3392,2965,2925,2868$, 1649, 1451, 1372, 1261, 1084, 966, $773 \mathrm{~cm}^{-1} .{ }^{1} \mathrm{H}$ NMR $(300.13 \mathrm{MHz}$, $\left.\mathrm{CDCl}_{3}\right): \delta 1.19\left(\mathrm{~d},{ }^{3} \mathrm{JHH}_{\mathrm{H}}=6.5 \mathrm{~Hz}, 3 \mathrm{H}\right), 1.44(\mathrm{br} \mathrm{s}, 2 \mathrm{H}), 3.53-3.62(\mathrm{~m}, 1 \mathrm{H})$, $6.02\left(\mathrm{dd},{ }^{3} \mathrm{JHH}=15.9,{ }^{3} \mathrm{JHH}=6.7 \mathrm{~Hz}, 1 \mathrm{H}\right), 6.43\left(\mathrm{dd},{ }^{3} \mathrm{JHH}_{\mathrm{HH}}=15.9,{ }^{4} \mathrm{JHH}=0.5\right.$ $\mathrm{Hz}, 1 \mathrm{H}), 7.06\left(\mathrm{dd},{ }^{4} \mathrm{JHH}=3.0,{ }^{4} \mathrm{JHH}=1.3 \mathrm{~Hz}, 1 \mathrm{H}\right), 7.16\left(\mathrm{dd},{ }^{3} \mathrm{JHH}_{\mathrm{HH}}=5.0,{ }^{4} \mathrm{JHH}\right.$ $=1.2 \mathrm{~Hz}, 1 \mathrm{H}), 7.21\left(\mathrm{dd},{ }^{3} \mathrm{JHH}_{\mathrm{HH}}=5.1,{ }^{4} \mathrm{JHH}=2.9 \mathrm{~Hz}, 1 \mathrm{H}\right) \mathrm{ppm} .{ }^{13} \mathrm{C} \mathrm{NMR}(75.5$ $\left.\mathrm{MHz}, \mathrm{CDCl}_{3}\right): \delta 23.9\left(\mathrm{CH}_{3}\right), 49.2(\mathrm{CH}), 121.4(\mathrm{CH}), 122.0(\mathrm{CH}), 125.0(\mathrm{CH})$, $125.9(\mathrm{CH}), 136.1(\mathrm{CH}), 139.7(\mathrm{C}) \mathrm{ppm}$. HRMS $\left(\mathrm{ESI}^{+}, \mathrm{m} / \mathrm{z}\right)$ : calcd for $\left(\mathrm{C}_{8} \mathrm{H}_{12} \mathrm{NS}\right)^{+}(\mathrm{M}+\mathrm{H})^{+}$154.0685, found: 154.0683 . 


\section{Typical procedure for the synthesis of amines $3 k$ and $\left.3\right|^{[68]}$}

An aqueous solution of conc. sulfuric acid (490 mg, $5 \mathrm{mmol}$ ) in dry acetonitrile $(2 \mathrm{~mL})$ was added to a stirred solution of the corresponding alcohol $1 \mathrm{k}$ or $1 \mathrm{l}(1 \mathrm{mmol})$ and $\mathrm{Na}_{2} \mathrm{SO}_{4}(142 \mathrm{mg}, 1 \mathrm{mmol})$ in dry acetonitrile $(3.1 \mathrm{~mL})$ at $0{ }^{\circ} \mathrm{C}$. The mixture was allowed to reach room temperature, and the stirring was continued for $24 \mathrm{~h}$. The mixture was concentrated under reduced pressure, and then cold water was added and the mixture extracted with diethyl ether $(3 \times 15 \mathrm{~mL})$. The combined organic layers were dried over anhydrous $\mathrm{Na}_{2} \mathrm{SO}_{4}$ and filtered. After evaporation of the solvent under reduced pressure, the corresponding acetamides $(1 \mathrm{mmol})$ were dissolved in a $6 \mathrm{M} \mathrm{HCl}$ aqueous solution $(5.7 \mathrm{~mL})$ and heated at $80{ }^{\circ} \mathrm{C}$ for $16 \mathrm{~h}$. The resulting solution was basified by addition of a $4 \mathrm{M} \mathrm{NaOH}$ aqueous solution to $\mathrm{pH} 10$ and extracted with diethyl ether $(3 \times 15 \mathrm{~mL})$. The combined organic layers were dried over anhydrous $\mathrm{Na}_{2} \mathrm{SO}_{4}$ and filtered. After evaporation of the solvent under reduced pressure, the corresponding amines $\mathbf{3 k}$ and $\mathbf{3}$ I were obtained with high purity in 47 and $58 \%$ yield, respectively.

(E)-4-(Pyridin-2-yl)but-3-en-2-amine (3k). Yellow oil $(70 \mathrm{mg}, 47 \%$ yield). $R_{\mathrm{f}}\left(5 \% \mathrm{NH}_{3} / \mathrm{MeOH}\right): 0.68$. IR $(\mathrm{NaCl}): 3353,3278,3005,2965,2925,2869$, $1653,1587,1564,1470,1432,1370,1300,1150,974,767,742 \mathrm{~cm}^{-1} .{ }^{1} \mathrm{H}$ $\operatorname{NMR}\left(300.13 \mathrm{MHz}, \mathrm{CDCl}_{3}\right): \delta 1.07\left(\mathrm{~d},{ }^{3} \mathrm{JHH}_{\mathrm{HH}}=6.6 \mathrm{~Hz}, 3 \mathrm{H}\right), 1.64(\mathrm{br} \mathrm{s}, 2 \mathrm{H})$, 3.46-3.55 (m, 1H), $6.36\left(\mathrm{dd},{ }^{3} \mathrm{~J}_{\mathrm{HH}}=15.7,{ }^{4} \mathrm{~J}_{\mathrm{HH}}=1.2 \mathrm{~Hz}, 1 \mathrm{H}\right), 6.54\left(\mathrm{dd},{ }^{3} \mathrm{JHH}_{\mathrm{HH}}\right.$ $\left.=15.8,{ }^{3} \mathrm{JHH}_{\mathrm{HH}}=6.3 \mathrm{~Hz}, 1 \mathrm{H}\right), 6.90\left(\mathrm{ddd},{ }^{3} \mathrm{~J}_{\mathrm{HH}}=7.5,{ }^{3} \mathrm{~J}_{\mathrm{HH}}=4.9,{ }^{4} \mathrm{JHH}_{\mathrm{HH}}=1.2 \mathrm{~Hz}\right.$, $1 \mathrm{H}$ ), 7.07 (apparent dt, ${ }^{3} \mathrm{~J}_{\mathrm{HH}}=7.9,{ }^{4} \mathrm{~J}_{\mathrm{HH}}=1.1 \mathrm{~Hz}, 1 \mathrm{H}$ ), 7.40 (apparent td, $\left.{ }^{3} \mathrm{~J}_{\mathrm{HH}}=7.7,{ }^{4} \mathrm{~J}_{\mathrm{HH}}=1.8 \mathrm{~Hz}, 1 \mathrm{H}\right), 8.34\left(\mathrm{ddd},{ }^{3} \mathrm{JHH}_{\mathrm{HH}}=4.9,{ }^{4} \mathrm{~J}_{\mathrm{HH}}=1.9,{ }^{5} \mathrm{JHH}_{\mathrm{HH}}=1.0\right.$ $\mathrm{Hz}, 1 \mathrm{H})$ ppm. ${ }^{13} \mathrm{C}$ NMR $\left(75.5 \mathrm{MHz}, \mathrm{CDCl}_{3}\right): \delta 23.4\left(\mathrm{CH}_{3}\right), 48.7(\mathrm{CH}), 121.1$ $(\mathrm{CH}), 121.6(\mathrm{CH}), 127.3(\mathrm{CH}), 136.2(\mathrm{CH}), 140.5(\mathrm{CH}), 149.1(\mathrm{CH}), 155.3$ (C) ppm. HRMS $\left(\mathrm{ESI}^{+}, \mathrm{m} / \mathrm{z}\right)$ : calcd for $\left(\mathrm{C}_{9} \mathrm{H}_{13} \mathrm{~N}_{2}\right)^{+}(\mathrm{M}+\mathrm{H})^{+} 149.1073$, found: 149.1076 .

(E)-4-(Pyridin-3-yl)but-3-en-2-amine (3I). Yellow oil (86 mg, 58\% yield). $R_{\mathrm{f}}\left(5 \% \mathrm{NH}_{3} / \mathrm{MeOH}\right): 0.62$. IR $(\mathrm{NaCl}): 3351,3275,3029,2967,2926,2869$, $1663,1587,1570,1480,1453,1416,1371,1024,969,847,828,709 \mathrm{~cm}^{-}$ 1. ${ }^{1} \mathrm{H}$ NMR $\left(300.13 \mathrm{MHz}, \mathrm{CDCl}_{3}\right): \delta 1.12\left(\mathrm{~d},{ }^{3} \mathrm{~J}_{\mathrm{HH}}=6.6 \mathrm{~Hz}, 3 \mathrm{H}\right), 1.46(\mathrm{br} \mathrm{s}$, $2 \mathrm{H}), 3.50-3.59(\mathrm{~m}, 1 \mathrm{H}), 6.15\left(\mathrm{dd},{ }^{3} \mathrm{~J}_{\mathrm{HH}}=16.0,{ }^{3} \mathrm{~J}_{\mathrm{HH}}=6.3 \mathrm{~Hz}, 1 \mathrm{H}\right), 6.31(\mathrm{~d}$, $\left.{ }^{3} \mathrm{~J}_{\mathrm{HH}}=16.0 \mathrm{~Hz}, 1 \mathrm{H}\right), 7.08\left(\mathrm{dd},{ }^{3} \mathrm{~J}_{\mathrm{HH}}=8.0,{ }^{3} \mathrm{~J}_{\mathrm{HH}}=4.8 \mathrm{~Hz}, 1 \mathrm{H}\right), 7.54$ (apparent $\left.\mathrm{dt},{ }^{3} \mathrm{JHH}_{\mathrm{HH}}=8.0,{ }^{4} \mathrm{JHH}_{\mathrm{HH}}=1.9 \mathrm{~Hz}, 1 \mathrm{H}\right), 8.29\left(\mathrm{dd},{ }^{3} \mathrm{JHH}_{\mathrm{HH}}=4.8,{ }^{4} \mathrm{~J}_{\mathrm{HH}}=1.6 \mathrm{~Hz}, 1 \mathrm{H}\right)$, $8.44\left(\mathrm{~d},{ }^{4} \mathrm{~J}_{\mathrm{HH}}=2.1 \mathrm{~Hz}, 1 \mathrm{H}\right) \mathrm{ppm} .{ }^{13} \mathrm{C} \mathrm{NMR}\left(75.5 \mathrm{MHz}, \mathrm{CDCl}_{3}\right): \delta 23.7\left(\mathrm{CH}_{3}\right)$, $49.0(\mathrm{CH}), 123.3(\mathrm{CH}), 124.0(\mathrm{CH}), 132.5(\mathrm{CH}), 132.6(\mathrm{C}), 138.4(\mathrm{CH})$, $148.0(\mathrm{CH}), 148.1(\mathrm{CH})$ ppm. HRMS $\left(\mathrm{ESI}^{+}, \mathrm{m} / \mathrm{z}\right)$ : calcd for $\left(\mathrm{C}_{9} \mathrm{H}_{13} \mathrm{~N}_{2}\right)^{+}$ $(\mathrm{M}+\mathrm{H})^{+}$149.1073, found: 149.1076 .

\section{General procedure for the laccase-catalysed oxidation of alcohols} 1a-p

In an open-to-air test tube, TEMPO (4.1 mg, $33 \mathrm{~mol} \%$ ) was added to a solution of the corresponding racemic alcohol 1a-p $(0.08 \mathrm{mmol}, 100 \mathrm{mM})$ in a biphasic mixture of oxygen-saturated citrate buffer $50 \mathrm{mM} \mathrm{pH} 5$ and MTBE $(50 \% \mathrm{v} / \mathrm{v}$ for a total volume of $800 \mu \mathrm{L})$. The reaction mixture was magnetically stirred for a few minutes to dissolve all the reagents and then the laccase from Trametes versicolor was added (7 mg, $4.6 \mathrm{U})$, and the mixture magnetically stirred $(150 \mathrm{rpm})$ for additional $16 \mathrm{~h}$ at $30 \stackrel{\circ}{ } \mathrm{C}$. After this time, the product was extracted with EtOAc $(2 \times 2 \mathrm{~mL})$, the organic phases combined, dried over $\mathrm{Na}_{2} \mathrm{SO}_{4}$, filtered and an aliquot was taken for the determination of the conversion value by GC analysis (see Tables 1 and $2,>98 \%$ conversion into ketones $\mathbf{2 a - p}$ ).

\section{General procedure for the biotransamination of ketones 2a-p}

In an Eppendorf vial, the corresponding ketone $2 \mathbf{a}-\mathbf{p}(5 \mu \mathrm{mol}, 10 \mathrm{mM})$ was dissolved in DMSO $(2.5 \% \mathrm{v} / \mathrm{v}, 12 \mu \mathrm{L})$. Then, a phosphate buffer $100 \mathrm{mM}$
$\mathrm{pH} 7.5(485 \mu \mathrm{L})$ containing PLP $(1 \mathrm{mM})$ and isopropylamine $(1.0 \mathrm{M})$ and the corresponding commercially available ATA $(2 \mathrm{mg})$ were added. The reaction was shaken at $45^{\circ} \mathrm{C}$ and $250 \mathrm{rpm}$ for $24 \mathrm{~h}$ and then stopped by the addition of a $\mathrm{NaOH} 10 \mathrm{M}$ aqueous solution $(200 \mu \mathrm{L})$. The mixture was extracted with EtOAc $(500 \mu \mathrm{L})$ and the organic layer was separated by centrifugation (2 min, 13,000 rpm). This extraction and centrifugation protocol was performed twice, and the organic layers were combined and dried over $\mathrm{Na}_{2} \mathrm{SO}_{4}$. Conversion and enantiomeric excess values were determined by GC (see Tables 3, 4 and others in the Supporting Information file).

Typical procedure for the sequential two-step synthesis of enantioenriched amines $3 a-p$ from racemic alcohols $1 a-p$

In an open-to-air test tube, TEMPO $(4.1 \mathrm{mg}, 33 \mathrm{~mol} \%)$ was added to a solution of the corresponding racemic alcohol 1a-p $(0.08 \mathrm{mmol}, 100 \mathrm{mM})$ in a biphasic mixture of an oxygen-saturated citrate buffer $50 \mathrm{mM} \mathrm{pH} 5$ and MTBE $(50 \% \mathrm{v} / \mathrm{v}$, for a total volume of $800 \mu \mathrm{L})$. The reaction mixture was stirred for a few minutes to dissolve all the reagents, and then the laccase from Trametes versicolor $(7 \mathrm{mg}, 4.6 \mathrm{U}$ ) was added. The reaction was stirred for $16 \mathrm{~h}$ at $30^{\circ} \mathrm{C}$, observing the complete evaporation of MTBE along this time. This fact led to a volume reduction from the initial $800 \mu \mathrm{L}$ to $400 \mu \mathrm{L}$, and as a consequence, the substrate concentration increased from the initial $100 \mathrm{mM}$ to approximately $200 \mathrm{mM}$. The resulting reaction crude containing the ketone intermediate $\mathbf{2 a - p}$ was transferred to a $15 \mathrm{~mL}$ centrifuge tube, and then DMSO $(0.2 \mathrm{~mL})$, phosphate buffer $100 \mathrm{mM} \mathrm{pH}$ $7.6(7.4 \mathrm{~mL})$ containing isopropylamine $(1.08 \mathrm{M})$, and PLP $(2 \mathrm{mg})$ were added, leading to a concentration approximately of $10 \mathrm{mM}$ for the substrate, $1 \mathrm{M}$ for isopropylamine, $1 \mathrm{mM}$ for PLP and $2.5 \% \mathrm{v} / \mathrm{v}$ of DMSO. At the same time, the addition of this concentrated buffer to the reaction media, caused an increase in the $\mathrm{pH}$ from an initial value of 5 to approximately 7.5 , therefore, further $\mathrm{pH}$ adjustment was not required for the biotransamination reaction. Finally, the corresponding commercially available amine transaminase $(24 \mathrm{mg})$ was added. The centrifuge tube was closed and the reaction shaken at $45^{\circ} \mathrm{C}$ and $250 \mathrm{rpm}$ for $24 \mathrm{~h}$. After this time, the reaction was stopped by addition of a $\mathrm{NaOH} 10 \mathrm{M}$ aqueous solution $(3 \mathrm{~mL})$. The mixture was extracted with EtOAc $(5 \mathrm{~mL})$ and the organic layer was separated by centrifugation ( $3 \mathrm{~min}, 4,900 \mathrm{rpm}$ ). This extraction and centrifugation protocol was performed twice and, finally, the organic layers were combined and dried over $\mathrm{Na}_{2} \mathrm{SO}_{4}$. Conversion values into the corresponding enantioenriched amines $\mathbf{3 a - p}$ were determined by GC analyses. Derivatisation of the amines 3a-p as acetamide derivatives with acetic anhydride in the presence of potassium carbonate was necessary for the measurement of their enantiomeric excess values.

Semi-preparative sequential two-step bioamination of alcohols $1 \mathrm{a}, \mathrm{b}$, g and $o$

In an open-to-air test tube, TEMPO (8.2 mg, $33 \mathrm{~mol} \%$ ) was added to a solution of the corresponding racemic alcohol $\mathbf{1 a}, \mathbf{b}, \mathbf{g}$ or $\mathbf{0}(0.16 \mathrm{mmol}$, $100 \mathrm{mM}$ ) in a biphasic mixture of an oxygen-saturated citrate buffer $50 \mathrm{mM}$ $\mathrm{pH} 5$ and MTBE $(50 \% \mathrm{v} / \mathrm{v}$, for a total volume of $1.6 \mathrm{~mL})$. The reaction mixture was stirred for a few minutes to dissolve all the reagents, and then the laccase from Trametes versicolor $(14 \mathrm{mg}, 9.2 \mathrm{U}$ ) was added. The reaction was stirred for $16 \mathrm{~h}$ at $30 \stackrel{\circ}{ } \mathrm{C}$, observing the complete evaporation of MTBE along this time. This fact led to a volume reduction from the initial $1.6 \mathrm{~mL}$ to $800 \mu \mathrm{L}$, and as a consequence, the substrate concentration increased from the initial $100 \mathrm{mM}$ to approximately $200 \mathrm{mM}$. The resulting reaction crude containing the ketone intermediate $\mathbf{2} \mathbf{a}, \mathbf{b}, \mathbf{g}$ or $\mathbf{o}$ was transferred to a $50 \mathrm{~mL}$ centrifuge tube, and then acetonitrile (MeCN, 0.4 $\mathrm{mL})$, phosphate buffer $100 \mathrm{mM} \mathrm{pH} 7.6(14.8 \mathrm{~mL})$ containing isopropylamine $(1.08 \mathrm{M})$, and PLP $(4 \mathrm{mg})$ were added, leading to a concentration approximately of $10 \mathrm{mM}$ for the substrate, $1 \mathrm{M}$ for isopropylamine, $1 \mathrm{mM}$ for PLP and $2.5 \% \mathrm{v} / \mathrm{v}$ of $\mathrm{MeCN}$. At the same time,

For internal use, please do not delete. Submitted_Manuscript 
the addition of this concentrated buffer to the reaction media, caused an increase in the $\mathrm{pH}$ from an initial value of 5 to approximately 7.5 , therefore, further $\mathrm{pH}$ adjustment was not required for the biotransamination reaction. Finally, the corresponding commercially available amine transaminase (48 $\mathrm{mg}$ ) was added. The centrifuge tube was closed and the reaction shaken at $45^{\circ} \mathrm{C}$ and $250 \mathrm{rpm}$ for $24 \mathrm{~h}$. After this time, the reaction was stopped by addition of a $\mathrm{NaOH} 10 \mathrm{M}$ aqueous solution $(6 \mathrm{~mL})$. The mixture was extracted with EtOAc $(10 \mathrm{~mL})$ and the organic layer was separated by centrifugation ( $3 \mathrm{~min}, 4,900 \mathrm{rpm}$ ). This extraction and centrifugation protocol was performed twice and, finally, the organic layers were combined and dried over $\mathrm{Na}_{2} \mathrm{SO}_{4}$. Conversion values into the corresponding enantioenriched amines $\mathbf{3 a}, \mathbf{b}, \mathbf{g}$ or $\mathbf{o}$ were determined by $\mathrm{GC}$ analyses. Optical rotation of enantiopure amine $3 a$ was determined to confirm the amine absolute configuration: $(R)-3 \mathrm{a}:[\alpha]_{D^{20}}=+21.5(\mathrm{c}=1.0$, $\mathrm{CHCl}_{3},>99 \%$ ee). Lit: $[\alpha]_{D}^{20}=+25.8\left(\mathrm{c}=1.16, \mathrm{CHCl}_{3},>99 \%\right.$ ee). ${ }^{[15]}$ Then, the optical rotation values of novel optically active amines $\mathbf{3 b}, \mathbf{3 g}$ and $\mathbf{3 0}$ were also calculated: $(S)-3 \mathbf{b}:[\alpha]_{D}^{20}=-34.6\left(\mathrm{c}=1.0, \mathrm{CHCl}_{3},>99 \%\right.$ ee); (S)3g: $[\alpha]_{D^{20}}=-23.5\left(\mathrm{c}=1.0, \mathrm{CHCl}_{3}, 99 \%\right.$ ee); $(R)-3 \mathrm{o}:[\alpha]_{D^{20}}=+20.8(\mathrm{c}=1.0$, $\mathrm{CHCl}_{3},>99 \%$ ee). Derivatisation of these amines as acetamide derivatives with acetic anhydride in the presence of potassium carbonate was necessary for the measurement of their enantiomeric excess values, and the elution times were compared with those previously described ${ }^{[17]}$ to assign the absolute configurations of the allylic amines obtained by this enzymatic approach.

\section{Acknowledgements}

Financial support from the Spanish Ministry of Economy and Competitiveness (MEC, Project CTQ2016-75752-R) and the Asturian regional government (FC-GRUPIN-IDI/2018/000181) are gratefully acknowledged. J.A.-V. also thanks the Asturian regional government for a predoctoral fellowship inside the Severo Ochoa programme. Prof. Wolfgang Kroutil (University of Graz, Austria) is acknowledged for the donation of overexpressed amine transaminases.

Keywords: allylic amines $\cdot$ amination of alcohols $\cdot$ amine transaminases $\cdot$ cascade reactions $\cdot$ laccases

[1] A. Lauren, P. Mison, A. Nafti, Synthesis 1983, 685-700.

[2] B. M. Trost, T. Zhang, J. D. Sieber, Chem. Sci. 2010, 1, 427-440.

[3] A. Stütz, Angew. Chem. Int. Ed. 1987, 26, 320-328; Angew. Chem. 1987, 99, 323-331.

[4] S. Chackalamannil, R. Davies, Org. Lett. 2001, 3, 1427-1429.

[5] D. A. Oliveira, D. G. Pereira, A. M. A. P. Fernandes, S. L. De Castro, A. R. M. Souza Brito, A. O. De Souza, N. Durán, Parasitol. Res. 2005, 95, 161-166.

[6] G. K. Friestad, T. Jiang, A. K. Mathies, Org. Lett. 2007, 9, 777-780.

[7] A. Farwick, G. Helmchen, Org. Lett. 2010, 12, 1108-1111.

[8] W.-Y. Zhang, P. C. Hogan, C.-L. Chen, J. Niu, Z. Wang, D. Lafrance, O. Gilicky, N. Dunwoody, M. Ronn, Org. Process Res. Dev. 2015, 19, 17841795.

[9] B. M. Trost, M. L. Crawley, Chem. Rev. 2003, 103, 2921-2944.

[10] S. Nag, S. Batra, Tetrahedron 2011, 67, 8959-9061.

[11] E. M. Skoda, G. C. Davis, P. Wipf, Org. Process Res. Dev. 2012, 16, 26 34.

[12] E. G. Klauber, N. Mittal, T. K. Shah, D. Seidel, Org. Lett. 2011, 13, 24642467.

[13] Y. Wang, Y.-N. Xu, G.-S. Fang, H.-J. Kang, Y. Gu, S.-K. Tian, Org. Biomol. Chem. 2015, 13, 5367-5371.

[14] T. G. Schenck, B. Bosnich, J. Am. Chem. Soc. 1985, 107, 2058-2066.
[15] A. R. Katritzky, D. Cheng, J. Li, J. Org. Chem. 1998, 63, 3438-3444.

[16] K. Xu, Y.-H. Wang, V. Khakyzadeh, B. Breit, Chem. Sci. 2016, 7, 33133316

[17] T.-L. Liu, C.-J. Wang, X. Zhang, Angew. Chem. Int. Ed. 2013, 52, 8416 8419; Angew. Chem. 2013, 125, 8574-8577.

[18] E. Selva, Y. Sempere, D. Ruiz-Martínez, Ó. Pablo, D. Guijarro, J. Org Chem. 2017, 82, 13693-13699.

[19] X.-W. Qian, Z.-J. Xue, Q. Zhao, Z. Cui, Y.-J. Chen, C.-G. Feng, G.-Q. Lin Org. Lett. 2017, 19, 5601-5604

[20] S.-I. Murahashi, Y. Taniguchi, Y. Imada, Y. Tanigawa, J. Org. Chem. 1989, 54, 3292-3303.

[21] M. Höhne, U. T. Bornscheuer, ChemCatChem 2009, 1, 42-51.

[22] V. Gotor-Fernández, V. Gotor, Curr. Opin. Drug Discov. Dev. 2009, 12, 784-797.

[23] Chiral Amine Synthesis: Methods, Developments and Applications, (Ed.: T. C. Nugent), Wiley-VCH, Weinheim, 2010

[24] D. Ghislieri, N. J. Turner, Top. Catal. 2014, 57, 284-300.

[25] G. Grogan, Curr. Opin. Chem. Biol. 2018, 43, 15-22.

[26] M D. Patil, G. Grogan, A. Bommarius, H. Yun, ACS Catal. 2018, 8 , 10985-11015.

[27] R. C. Simon, N. Richter, E. Busto, W. Kroutil, ACS Catal. 2014, 4, 129143.

[28] V. Köhler, N. J. Turner, Chem. Commun. 2015, 51, 450-464.

[29] J. Muschiol, C. Peters, N. Oberleitner, M. D. Mihovilovic, U. T. Bornscheuer, F. Rudroff, Chem. Commun. 2015, 51, 5798-5811.

[30] M. Hönig, P. Sondermann, N. J. Turner, E. M. Carreira, Angew. Chem Int. Ed. 2017, 56, 8942-8973; Angew. Chem. 2017, 129, 9068-9100.

[31] S. Schmidt, K. Castiglione, R. Kourist, Chem. Eur. J. 2018, 24, 1755 1768.

[32] J. H. Schrittwieser, S. Velikogne, M. Hall, W. Kroutil, Chem. Rev. 2018, 118, 270-348

[33] W. Zhang, E. Fernández-Fueyo, Y. Ni, M. van Schie, J. Gacs, R. Renirie, R. Wever, F. G. Mutti, D. Rother, M. Alcalde, F. Hollmann, Nat. Catal. 2018, 1, 55-62.

[34] K. Tauber, M. Fuchs, J. H. Sattler, J. Pitzer, D. Pressnitz, D. Koszelewski, K. Faber, J. Pfeffer, T. Haas, W. Kroutil, Chem. Eur. J. 2013, 19, 40304035.

[35] A. Lerchner, S. Achatz, C. Rausch, T. Haas, A. Skerra, ChemCatChem 2013, 5, 3374-3383

[36] F. G. Mutti, T. Knaus, N. S. Scrutton, M. Breuer, N. J. Turner, Science 2015, 349, 1525-1529.

[37] F.-F. Chen, Y.-Y. Liu, G.-W. Zheng, J.-H. Xu, ChemCatChem 2015, 7, 3838-3841.

[38] M. P. Thompson, N. J. Turner, ChemCatChem 2017, 9, 3833-3836.

[39] T. Knaus, L. Cariati, M. F. Masman, F. G. Mutti, Org. Biomol. Chem. 2017, 15, 8313-8325.

[40] W. Böhmer, T. Knaus, F. G. Mutti, ChemCatChem 2018, 10, 731-735.

[41] J. Liu, Z. Li, Biotechnol. Bioeng. 2019, 116, 536-542.

[42] J. A. Houwman, T. Knaus, M. Costa, F. G. Mutti, Green Chem. 2019, 21 , 3846-3857.

[43] A. Gomm, S. Grigoriou, C. Peel, J. Ryan, N. Mujtaba, T. Clarke, E. Kulcinskaja, E. O'Reilly, Eur. J. Org. Chem. 2018, 5282-5284.

[44] S. Riva, Trends Biotechnol. 2006, 24, 219-226.

[45] S. Witayakran, A. J. Ragauskas, Adv. Synth. Catal. 2009, 351, 1187 1209.

[46] M. D. Cannatelli, A. J. Ragauskas, Chem. Rec. 2017, 17, 122-140.

[47] S. G. Burton, Curr. Org. Chem. 2003, 7, 1317-1331.

[48] M. Mogharabi, M. A. Faramarzi, Adv. Synth. Catal. 2014, 356, 897-927.

[49] I. Gonçalves, C. Silva, A. Cavaco-Paulo, Green Chem. 2015, 17, 1362 1374

[50] A. Díaz-Rodríguez, I. Lavandera, S. Kanbak-Aksu, R. A. Sheldon, V. Gotor, V. Gotor-Fernández, Adv. Synth. Catal. 2012, 354, 3405-3408.

[51] A. Díaz-Rodríguez, L. Martínez-Montero, I. Lavandera, V. Gotor, V. Gotor-Fernández, Adv. Synth. Catal. 2014, 356, 2321-2329.

For internal use, please do not delete. Submitted_Manuscript 
[52] A. Díaz-Rodríguez, N. Ríos-Lombardía, J. H. Sattler, I. Lavandera, V. Gotor-Fernández, W. Kroutil, V. Gotor, Catal. Sci. Technol. 2015, 5, 1443-1446.

[53] K. Kędziora, A. Díaz-Rodríguez, I. Lavandera, V. Gotor-Fernández, V. Gotor, Green Chem. 2014, 16, 2448-2453.

[54] L. Martínez-Montero, V. Gotor, V. Gotor-Fernández, I. Lavandera, Green Chem. 2017, 19, 474-480.

[55] L. Martínez-Montero, V. Gotor, V. Gotor-Fernández, I. Lavandera, ACS Catal. 2018, 8, 2413-2419.

[56] W. Gładkowski, A. Skrobiszewski, M. Mazur, M. Siepka, A. Pawlak, B. Obmińska-Mrukowicz, A. Białońska, D. Poradowski, A. Drynda, M. Urbaniak, Tetrahedron 2013, 69, 10414-10423.

[57] F. Guo, P. Berglund, Green Chem. 2017, 19, 333-360.

[58] I. Slabu, J. L. Galman, R. C. Lloyd, N. J. Turner, ACS Catal. 2017, 7, 8263-8284.

[59] M. D. Patil, G. Grogan, A. Bommarius, H. Yun, Catalysts 2018, 8, 254

[60] A. Gomm, E. O'Reilly, Curr. Opin. Chem. Biol. 2018, 43, 106-112.

[61] P. Kelefiotis-Stratidakis, T. Tyrikos-Ergas, I. V. Pavlidis, Org. Biomol. Chem. 2019, 17, 1634-1642.
[62] U. Kaulman, K. Smithies, M. E. B. Smith, H. C. Hailes, J. M. Ward Enzyme Microb. Technol. 2007, 41, 628-637.

[63] S. Pannuri, S. V. Kamat, A. R. M. Garcia, (Cambrex North Brunswick Inc.), PCT Int. Appl. 2006, WO 2006063336 A2 20060615.

[64] Y. Yamada, A. Iwasaki, N. Kizaki (Kaneka Corporation), EP 0987332 A1, 2000.

[65] A. Iwasaki, Y. Yamada, N. Kizaki, Y. Ikenaka, J. Hasegawa, Appl. Microbiol. Biotechnol. 2006, 69, 499-505.

[66] F. G. Mutti, C. S. Fuchs, D. Pressnitz, J. H. Sattler, W. Kroutil, Adv. Synth Catal. 2011, 353, 3227-3233.

[67] C. K. Savile, J. M. Janey, E. M. Mundorff, J. C. Moore, S. Tam, W. R. Jarvis, J. C. Colbeck, A. Krebber, F. J. Fleitz, J. Brands, P. N. Devine, G. W. Huisman, G. J. Georges, Science 2010, 329, 305-309.

[68] F. Messina, M. Botta, F. Corelli, M. P. Schneider, F. Fazio, J. Org. Chem. 1999, 64, 3767-3769. 


\section{Entry for the Table of Contents}

\section{FULL PAPER}

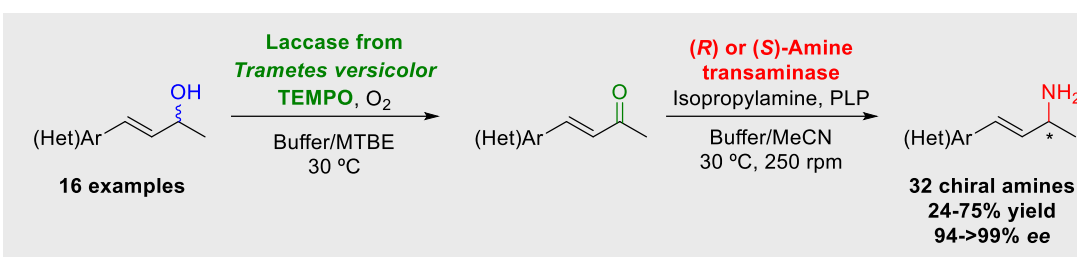

A sequential two-step amination of $(3 E)$-4-(het)arylbut-3-en-2-alcohols has been described through a sequential cascade. The approach consists in their laccase Trametes versicolor/TEMPO-mediated oxidation to form the corresponding ketone intermediates, followed by asymmetric biotransamination using amine transaminases. Satisfyingly, 16 amine enantiomer pairs were obtained in very high to excellent stereoselectivity $(94->99 \%$ ee) and moderate to good isolated yields (29-75\% isolated yield).
Jesús Albarrán-Velo, Iván Lavandera, * Vicente Gotor-Fernández*

Page No. - Page No.

Sequential Two-Step Stereoselective

Amination of Allylic Alcohols through Combination of Laccases and Amine

For internal use, please do not delete. Submitted_Manuscript 